\title{
Effect of paraquat-induced oxidative stress on gene expression and aging of the filamentous ascomycete Podospora anserina
}

\author{
Matthias Wiemer and Heinz D. Osiewacz* \\ Institute of Molecular Biosciences and Cluster of Excellence Frankfurt Macromolecular Complexes; Department of Biosciences; J W \\ Goethe University; Max-von-Laue-Str. 9, 60438 Frankfurt, Germany. \\ * Corresponding Author: Heinz D. Osiewacz, Molecular Developmental Biology, J W Goethe University, Max-von-Laue-Str. 9; 60438 \\ Frankfurt, Germany; Tel: +49 69798 29264; Fax: +49 69798 29263; Email: Osiewacz@bio.uni-frankfurt.de
}

\begin{abstract}
Aging of biological systems is influenced by various factors, conditions and processes. Among others, processes allowing organisms to deal with various types of stress are of key importance. In particular, oxidative stress as the result of the generation of reactive oxygen species (ROS) at the mitochondrial respiratory chain and the accumulation of ROS-induced molecular damage has been strongly linked to aging. Here we view the impact of ROS from a different angle: their role in the control of gene expression. We report a genome-wide transcriptome analysis of the fungal aging model Podospora anserina grown on medium containing paraquat $(\mathrm{PQ})$. This treatment leads to an increased cellular generation and release of $\mathrm{H}_{2} \mathrm{O}_{2}$, a reduced growth rate, and a decrease in lifespan. The combined challenge by $P Q$ and copper has a synergistic negative effect on growth and lifespan. The data from the transcriptome analysis of the wild type cultivated under PQ-stress and their comparison to those of a longitudinal aging study as well as of a copper-uptake longevity mutant of $P$. anserina revealed that $P Q$-stress leads to the upregulation of transcripts coding for components involved in mitochondrial remodeling. $P Q$ also affects the expression of copper-regulated genes suggesting an increase of cytoplasmic copper levels as it has been demonstrated earlier to occur during aging of $\boldsymbol{P}$. anserina and during senescence of human fibroblasts. This effect may result from the induction of the mitochondrial permeability transition pore via PQ-induced ROS, leading to programmed cell death as part of an evolutionary conserved mechanism involved in biological aging and lifespan control.
\end{abstract}

doi: $10.15698 / \operatorname{mic} 2014.07 .155$ Received originally: 10.04.2014; in revised form: 2.06.2014, Accepted 11.06.2014 Published 22.06.2014.

Keywords: Aging, paraquat, oxidative stress, transcriptome, copper, programmed cell death, mitochondria.

\author{
Abbreviations: $D A B, 3,3-$ \\ diaminobenzidine; juv, juvenile; \\ ma, middle-aged; MFRTA, \\ mitochondrial free radical theory of \\ aging; $P C D$, programmed cell death \\ $P Q$, paraquat; $R O S$, reactive oxygen \\ species; sen, senescent; \\ $S O D$, superoxide dismutase.
}

\section{INTRODUCTION}

Aging of biological systems is a complex process which is characterized by irreversible functional impairments and ultimately leads to death of the system. The process is under the control of genetic, environmental and stochastic traits. According to the 'mitochondrial free radical theory of aging' (MFRTA), impairments are caused by molecular damage resulting from the activity of reactive oxygen species (ROS) generated as by-products during respiration [1]. More recently, due to the accumulation of counterintuitive, non-consistent or even contradictory data, the MFRTA has been challenged [2, 3]. It appears that the rather simplistic relationship of ROS generation and the age- related accumulation of bulk molecular damage [4-6] are not sufficient to explain aging and a more complex scenario is effective [6-8] which remains to be elucidated in more detail.

We use Podospora anserina as an experimentally accessible aging model to elucidate the mechanistic basis of organismal aging $[9,10]$. This filamentous fungus is characterized by a short lifespan. Various pathways and processes including mitochondrial DNA instability [11], cellular copper homeostasis [12], respiration [13], ROS generation and scavenging [14], proteostasis $[15,16]$, mitochondrial dynamics [17], autophagy [18, 19], and apoptosis [20, 21] have been shown to affect aging. A recent age-related, 
genome-wide transcriptome analysis of the $P$. anserina wild type revealed evidence for interactions between pathways leading to compensatory effects once a particular component and pathway is affected [19].

Apart from their damaging role, ROS are active in signaling and control of gene expression. This function may link genetic, environmental and stochastic processes involved in aging and lifespan control and can help to explain unexpected and counter-intuitive experimental data. After having investigated genome-wide transcriptome profiles of $P$. anserina wild-type cultures of different age and of a long-lived mutant in which mitochondrial ROS generation is reduced compared to the wild type [22, 23], we now set out to analyze the impact of increased oxidative stress on global gene expression. Using paraquat (PQ) as a generator of the superoxide anion at the mitochondrial respiratory chain $[24,25]$, the site at which this ROS is generated also during normal aging, we experimentally induced strong cellular oxidative stress in wild-type cultures of different age and found that this treatment has profound effects on gene expression, growth and lifespan.

\section{RESULTS AND DISCUSSION}

\section{Dose-dependent induction of oxidative stress by $P Q$}

In a series of experiments, we investigated the response of the $P$. anserina wild type to $P Q$-stress. First, we determined the release of $\mathrm{H}_{2} \mathrm{O}_{2}$ by cultures of different age. These agespecific cultures were generated from mycelia that developed after germination of ascospores using pieces of these mycelia either directly (juvenile (juv) cultures) or after transfer to solid, PQ-free medium and incubation at $27^{\circ} \mathrm{C}$ for 5 days (middle-aged (ma) cultures) and 9-11 days (senescent (sen) cultures), respectively. From these cultures hyphal tips of the growth front were transferred to solid medium with different $P Q$ concentrations and cultured for four additional days. After this period of time, the release of $\mathrm{H}_{2} \mathrm{O}_{2}$ was visualized as a dark brown pigment that forms on agar plates after reaction with a 3,3-diaminobenzidine (DAB) containing solution (Figure 1A). An increase of $\mathrm{H}_{2} \mathrm{O}_{2}$ release during aging and after $P Q$ treatment was observed in particular at the growth front of senescent and of PQstressed cultures. For a quantitative and more detailed photometric analysis, we transferred cultures of defined age to 96-well plates, incubated them with DAB staining solution and determined the absorbance of the recovered solution (Figure 1B). In cultures of older age, a clear increase of $\mathrm{H}_{2} \mathrm{O}_{2}$ release is observed. Senescent cultures release approximately three times more $\mathrm{H}_{2} \mathrm{O}_{2}$ than juvenile cultures, verifying the known increase of oxidative stress during aging [17]. Consistently, also in cultures of different age ( 6 days, 11 days, 15 days) grown on medium containing $10 \mu \mathrm{M}$ and $20 \mu \mathrm{M} P Q$, respectively, a significant increase of $\mathrm{H}_{2} \mathrm{O}_{2}$ release is observed. The release is highest in senescent cultures grown on $20 \mu \mathrm{m} \mathrm{PQ}$.

Assumingly, the degree of $\mathrm{H}_{2} \mathrm{O}_{2}$ release by $P$. anserina cultures is proportional to cellular ROS levels in the organism. In order to validate this assumption experimentally, we investigated $P$. anserina strains expressing the gene coding for the redox sensitive HyPer reporter protein [26]. This protein is specifically oxidized by $\mathrm{H}_{2} \mathrm{O}_{2}$ and can be reverted to the reduced form by endogenous glutaredoxin. $P$. anserina strains expressing HyPer respond to the application of $\mathrm{H}_{2} \mathrm{O}_{2}$ by a change in fluorescence during excitation at $488 \mathrm{~nm}$ (oxidized HyPer) and $405 \mathrm{~nm}$ (reduced HyPer) in a dose-dependent manner. Repeated addition of $\mathrm{H}_{2} \mathrm{O}_{2}$ over time can be followed using this system (Figure $1 \mathrm{C}$ ). In accordance with the observed dose-dependent increase of $\mathrm{H}_{2} \mathrm{O}_{2}$ release from cultures subjected to increasing $P Q$ stress, strains expressing HyPer on media containing different concentrations of $P Q$ revealed a dose-dependent response of relative fluorescence ratios over time (Figure 1D). These data verify the conclusion that growth of $P$. anserina on $\mathrm{PQ}$-containing medium indeed increases endogenous (cellular) $\mathrm{H}_{2} \mathrm{O}_{2}$ stress.

\section{Age-dependent effect of PQ-stress on global gene expres- sion}

To analyze the impact of defined oxidative stress of $P$. anserina cultures of different age on gene expression and to compare this effect with existing data from a study of $P$. anserina cultures aged under standard growth conditions without PQ-stress [19], we treated cultures of the wild type of defined age ( 6 days, 11 days, 15 days) for $24 \mathrm{~h}$ with 200 $\mu \mathrm{M} P Q$ and subsequently isolated total RNA. In these experiments, we used a higher $P Q$ concentration than the concentration in experiments with solid PASM medium. This was necessary, because we aimed to induce strong effects on gene expression by oxidative stress and to investigate direct effects of superoxide rather than secondary effects that occur during longer exposure. Moreover, the effect of $P Q$ on growth is lower in complete medium used for the isolation of RNA (data not shown).

Using equal amounts of pooled RNA from three individual wild-type cultures, a SuperSAGE analysis was performed (GenXPro; Frankfurt, Germany). Between 14 and 20 million sequence tags were obtained for each sample, corresponding to about 10,000 of the 10,644 predicted $P$. anserina genes. Transcript counts of $\mathrm{PQ}$-stressed cultures were compared to those of an existing data set from a previous study of cultures of similar age, grown on standard PQ-free medium. For the identification of genes with a robust differential expression, we set the relative expression threshold to $>3$ and $\mathrm{pV}<0.01$.

Compared to juvenile ( 6 days) cultures grown on PQfree medium, 683 (594 plus 89) genes were found to be up-regulated in PQ-stressed cultures of the same age (Figure 2A; Table 1). In comparison, 509 (420 plus 89) transcripts were up-regulated in senescent cultures aged on standard growth medium. A comparison of the upregulated gene sets revealed that aging and $P Q$-stress has a similar effect on 89 transcripts (Figure 2A; Table 1). This number is significantly higher than the number of 35 which is statistically expected if regulation would be random and independent of ROS (Table 1). Since the experimentally administered $P Q$-stress is greater and more rigorous than it occurs during normal aging, where oxidative stress continuously increases over a longer period of time [27, 28], 
more genes (683) are induced in the PQ-stressed than in the 'aging' (509) group.

To further investigate the correlation of transcript regulation in different transcriptome data, Fisher's exact test was applied to give a measure of similarity of the compared transcriptome data. Since the investigated data sets revealed identical, low $p$-values of $<2.2 \mathrm{e}-16$, we calculated odds ratio provided by Fisher's exact test as a measure of similarity of two data sets. For instance, the comparison of up-regulated transcripts from cultures aged on PQ-free growth medium and PQ-stressed juvenile cultures revealed an odds ratio of 3.19 (Table 1). This indicates a 3.19 times higher probability of transcripts of one group (aging) to be also up-regulated in the other group (PQ-stressed). Overall, both statistical tests revealed for all compared sets of data a significant number of genes that are similarly regulated under the investigated conditions (e.g., PQ-stress, aging).

The number of genes which is down-regulated during PQ-stress of juvenile cultures $(1,172)$ and during aging (774) is higher than the number of up-regulated genes (683,
A

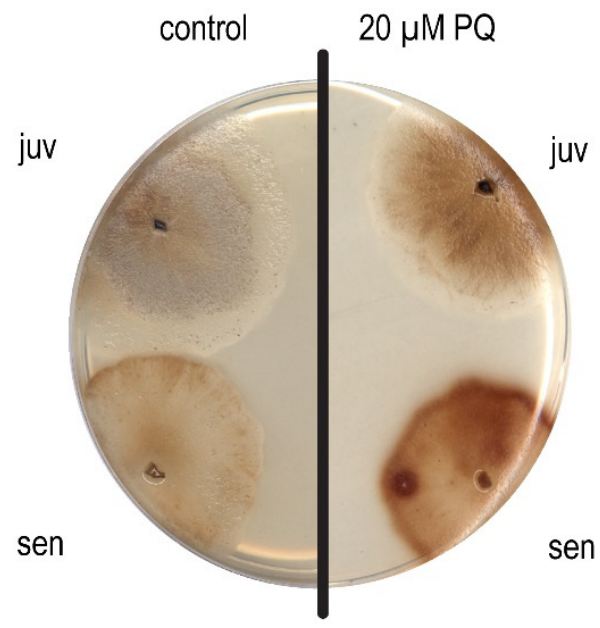

C

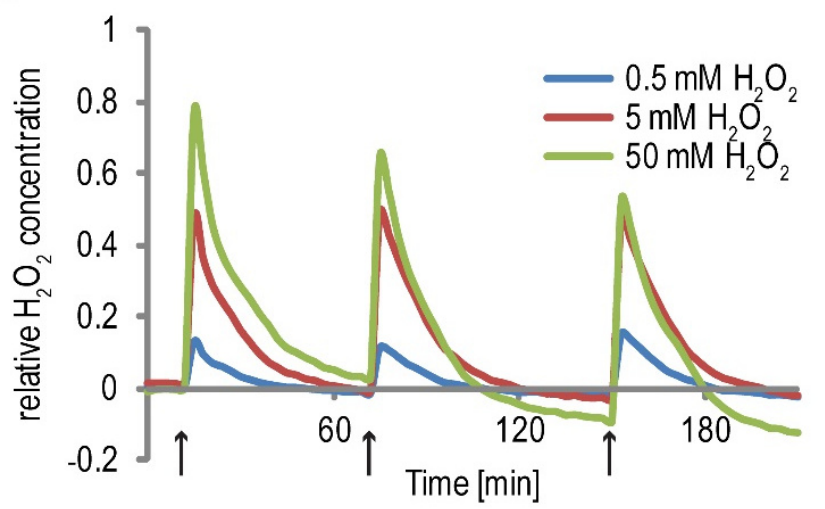

B

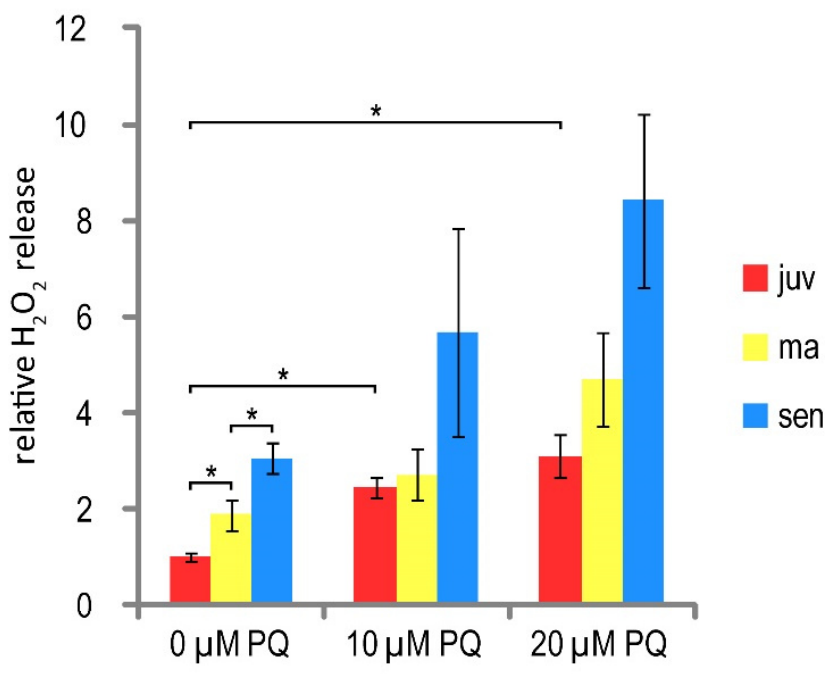

D

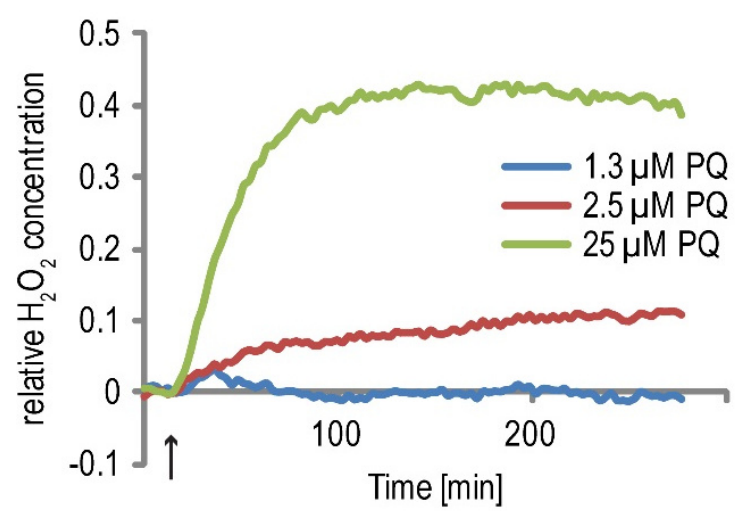

FIGURE 1: Increased hydrogen peroxide generation and release by $\boldsymbol{P}$. anserina cultures during aging and PQ-stress. (A) After 2 days of ascospore germination, fungal mycelia were either directly challenged with $20 \mu \mathrm{M} P Q$ (juv) or grown for 11 days on $\mathrm{M} 2$ medium to obtain a senescent stage. The cultures were subsequently incubated for 4 days on M2 with $20 \mu \mathrm{M}$ PQ. As a control, both age stages (juv: 6 days; sen: 17 days) were cultivated on $\mathrm{PQ}$-free $\mathrm{M} 2$ medium. After this time, DAB-staining-solution was poured on the cultures. The reaction with secreted $\mathrm{H}_{2} \mathrm{O}_{2}$ leads to the formation of a dark brown pigment. (B) Quantitative measurement of $\mathrm{H}_{2} \mathrm{O}_{2}$ release. $P$. anserina cultures were essentially grown as described in (A). Instead of on $M 2$, cultures were grown on PASM medium until reaching a final age of 6 days (juv), 11 days (ma) and 15 days (sen), respectively. Concentrations of $0 \mu \mathrm{M}, 10 \mu \mathrm{M}$ and $20 \mu \mathrm{M}$ PQ were administered. Bars indicate mean \pm standard error of $\mathrm{H}_{2} \mathrm{O}_{2}$ release relative to juvenile untreated cultures. $n=16-41$. Asterisks indicate $p V<0.01$. (C and $\mathbf{D}$ ) Relative changes in $\mathrm{H}_{2} \mathrm{O}_{2}$ concentration in the cytoplasm. $P$. anserina strains producing the redox sensitive HyPer protein, localized to the cytoplasm, were germinated for 2 days on germination medium and grown for 4 days on $\mathrm{M} 2$ agar plates. The mycelium was punched out of the agar, transferred to a 96 well plate and soaked in $60 \mu$ water. Subsequently, $\mathrm{H}_{2} \mathrm{O}_{2}$ (C) or PQ (D) was added at the indicated times (arrows) to a final concentration of $0.5 \mathrm{mM}, 5 \mathrm{mM}$ and $50 \mathrm{mM}$ or $1.3 \mu \mathrm{M}, 2.5 \mu \mathrm{M}$ and $25 \mu \mathrm{M}$, respectively. The fluorescence of the mycelium after exitation at $488 \pm 5 \mathrm{~nm}$ (oxidized HyPer) and $420 \pm 5 \mathrm{~nm}$ (reduced HyPer) was measured at $530 \pm 20 \mathrm{~nm}$. The graphs show the ratio of oxidized to reduced HyPer normalized to a untreated HyPer strain. 
509) (Figure 2A). We found 210 genes being downregulated during both $\mathrm{PQ}$-stress and normal aging. Again, this number is significantly higher than the 90 transcripts statistically expected if regulation would be random (Table 1). As indicated by similar odd rations (Table 1; odds ratio of 3.21 and 3.12, respectively) the proportion of similarly regulated genes is comparable in both, the up- and down regulated gene fraction.

During normal aging, oxidative stress increases continuously and individuals of different age have to deal with different levels of ROS (Figure 1). This situation may affect the ability to respond to exogenous PQ-stress in different directions. On the one hand, the age-related ROS accumulation could enhance survival during subsequent ROS treatment as a result of an adaptation to mild stress, a process called hormesis [29-31]. On the other hand, general fitness differs in cultures of different age. Cultures of older age may therefore be less effective in dealing with additional stress.

In order to test the effect of aging on the ability to deal with exogenous $\mathrm{PQ}$-stress, we compared the transcriptome data of $P$. anserina cultures of three different ages (juv, ma, sen) treated for $24 \mathrm{~h}$ with $200 \mu \mathrm{M} \mathrm{PQ}$. The data revealed 217 up-regulated and 576 down-regulated transcripts, respectively, in all three age stages after applying $P Q$-stress (Figure 2B). These are far more genes than the corresponding statistically expected number of 8 and 31 randomly regulated genes, indicating a controlled PQ-

\section{A}

up-regulated

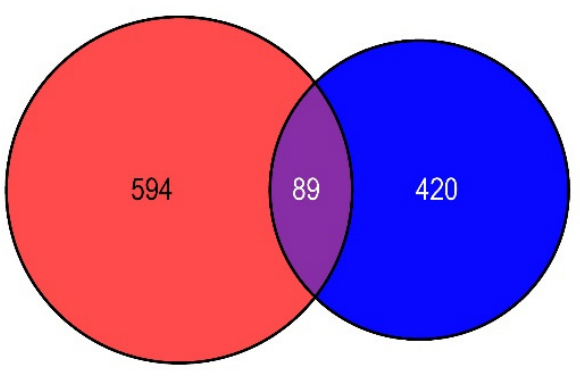

B

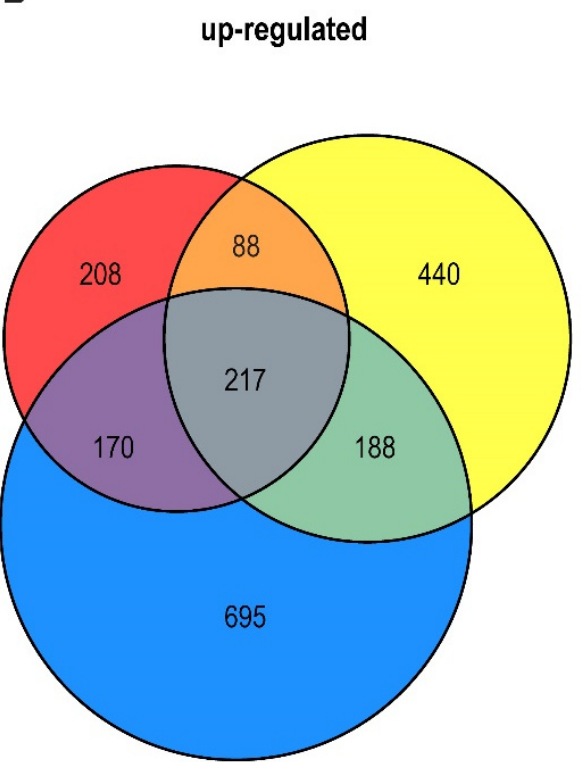

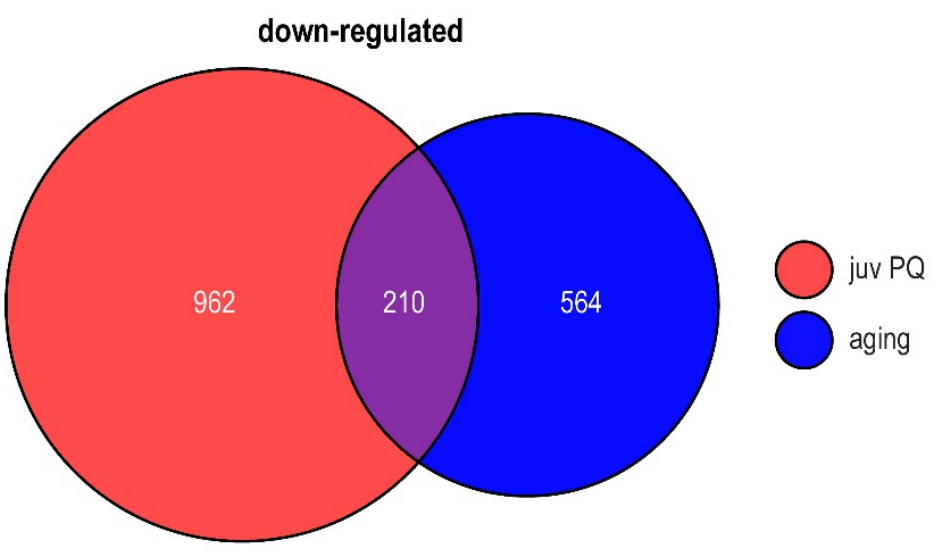

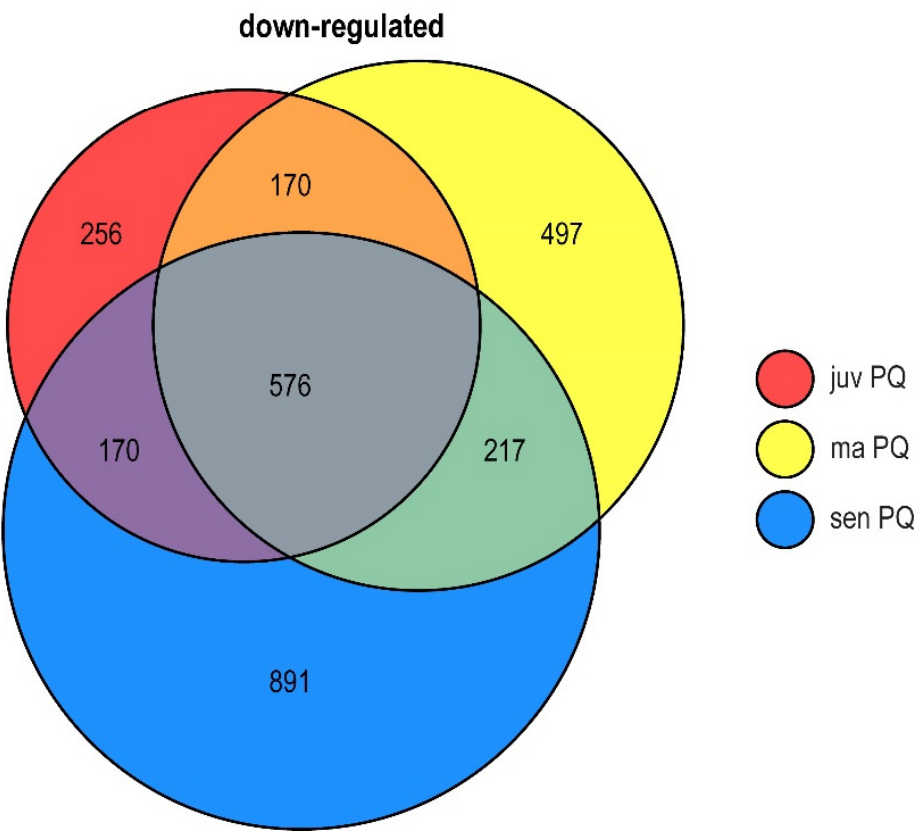

FIGURE 2: Differential transcript abundance during PQ-stress and aging. Venn diagrams of up- (left) and down- (right) regulated transcripts (factor 3; pV < 0.01) identified in transcriptome analysis. Factors are the quotient of tpm (tags per million) of treated ( $200 \mu \mathrm{M} \mathrm{PQ} \mathrm{for} 24 \mathrm{~h}$ or aging) and control samples. (A) Venn diagram of transcripts regulated in juvenile PQ-treated (juv $P Q=\operatorname{tpm} 6$ days PQ / tpm 6 days control, red) and aged cultures (tpm 14 days control/ tpm 6 days control, dark blue) and (B) juvenile PQ-treated (juv PQ = tpm 6 days $P Q /$ tpm 6 days control, red), middle-aged $P Q$-treated ( $m a P Q=$ tpm 11 days $P Q /$ tpm 11 days control, yellow) and senescent $P Q$-treated (sen $P Q=15$ days $\mathrm{PQ} / 14$ days control, light blue) $P$. anserina. The size of a circle represents the number of regulated transcripts. 
TABLE 1. Global gene regulation in the $P$. anserina wild type stressed by $P Q$ and during aging.

\begin{tabular}{|c|c|c|c|c|c|c|c|c|c|c|}
\hline & \multicolumn{2}{|c|}{ Aging / PQ juv } & \multicolumn{2}{|c|}{ PQ juv / PQ ma } & \multicolumn{2}{|c|}{$P Q$ juv / PQ sen } & \multicolumn{2}{|c|}{$P Q$ ma / PQ sen } & \multicolumn{2}{|c|}{ PQ juv / Grisea } \\
\hline & up & down & up & down & up & down & up & down & up & down \\
\hline Aging & 509 & 774 & & & & & & & & \\
\hline$P Q$ juv & 683 & 1172 & 683 & 1172 & 683 & 1172 & & & 683 & 1172 \\
\hline $\mathrm{PQ}$ ma & & & 933 & 1460 & & & 933 & 1460 & & \\
\hline$P Q$ sen & & & & & 1270 & 1854 & 1270 & 1854 & & \\
\hline Grisea & & & & & & & & & 608 & 556 \\
\hline $\begin{array}{l}\text { Conjoint } \\
\text { regulated }\end{array}$ & 89 & 210 & 305 & 746 & 387 & 746 & 405 & 793 & 167 & 267 \\
\hline $\begin{array}{c}\text { Stat. } \\
\text { expectation }\end{array}$ & 35 & 90 & 64 & 172 & 87 & 217 & 119 & 273 & 43 & 67 \\
\hline$p$-value & $\begin{array}{c}<2.2 \mathrm{e}- \\
16\end{array}$ & $\begin{array}{c}<2.2 \mathrm{e}- \\
16\end{array}$ & $\begin{array}{c}<2.2 \mathrm{e}- \\
16\end{array}$ & $\begin{array}{c}<2.2 \mathrm{e}- \\
16\end{array}$ & $\begin{array}{c}<2.2 \mathrm{e}- \\
16\end{array}$ & $\begin{array}{c}<2.2 \mathrm{e}- \\
16\end{array}$ & $\begin{array}{c}<2.2 \mathrm{e}- \\
16\end{array}$ & $\begin{array}{c}<2.2 \mathrm{e}- \\
16\end{array}$ & $\begin{array}{c}<2.2 \mathrm{e}- \\
16\end{array}$ & $\begin{array}{c}<2.2 \mathrm{e}- \\
16\end{array}$ \\
\hline Odds ratio & 3.19 & 3.21 & 11.06 & 19.71 & 12.51 & 12.23 & 7.20 & 8.30 & 6.29 & 8.41 \\
\hline
\end{tabular}

The table shows the number of differentially regulated genes (factor $<3 ; \mathrm{pV}<0.01$ ) of all analyzed transcriptome data. In the individual columns two data sets are compared (i.e. aging and PQ stress in juvenile cultures), respectively. The lines show the number of differentially expressed genes at the specified treatment. The amount of differentially regulated transcripts in the specific direction in both treatments is depicted in the line 'conjoint regulated'. The statistical expectation ('stat. expectation') provides the number of genes which is expected to be regulated if the two treatments initiate random gene regulation. The $p$-value was calculated by Fisher's exact test. Since the calculation of p-values lower than 2.2e-16 are identical, we included the odds ratio to clarify the level of similarity in transcript generation. The odds ratio is a measure for statistical dependence. A high odds ratio indicates a high probability for a regulation of a gene in the same direction during both compared condition.

dependent regulation of these genes, which is independent of age. Moreover, the comparison of the transcriptomes of cultures of different age (juv, ma, sen) treated with $P Q$ revealed that the number of differentially expressed genes increases with the age of the investigated culture. We found 683,933 , and 1,270 transcripts up- and 1,172, 1,460, and 1,854 transcripts down-regulated in juvenile, middleaged and senescent cultures, respectively (Figure 2B), indicating an age-dependent ROS regulation of gene expression with the strongest effect in strains of the oldest age, which also have the highest ROS levels (Figure 1B).

\section{Gene Ontology enrichment analysis}

In order to evaluate which molecular pathways respond to PQ-stress, we performed a Gene Ontology (GO) enrichment analysis of $P Q$-stress regulated genes in juvenile, 6 days old $P$. anserina cultures. Strikingly, genes encoding proteins of the 'mitochondrial matrix', the 'mitochondrial inner membrane' and the 'mitochondrial intermembrane space' as well as other categories related to mitochondria are enriched in the group of 683 genes up-regulated 3-fold or higher by PQ-stress (Table 2). It is possible that proteins in the vicinity of the ROS-generating electron transport chain are preferentially damaged during PQ-stress [32]. Up-regulation of these genes could compensate for dam- aged and degraded proteins. Concordantly, transcripts of genes coding for proteins involved in this kind of mitochondrial remodeling, including those active in transport of components into mitochondria, the organization of mitochondria, mitochondrial translation, ubiquinone biosynthesis and mitochondrial genome maintenance are enriched in the group of up-regulated genes (Table 2).

Among the 1,172 genes which are down-regulated at least 3-fold after applying $P Q$-stress to juvenile cultures (Figure 2A, right), no enrichment of transcripts coding for proteins located in a specific cellular compartment is found. Instead, GO terms for several biological processes are enriched (Table 2). The down-regulation of genes coding for components of 'melanin biosynthetic processes' and 'secondary metabolite biosynthetic process' is in concordance with the decreased pigmentation of cultures grown under $P Q$-stress (Figure 3). Both processes are energy consuming and therefore may be down-regulated. After applying $\mathrm{PQ}$ stress, the genes Pa_2_510, Pa_5_11880, Pa_7_11610, Pa_5_1990 coding for products involved in the synthesis of melanin [33] are down-regulated by factors between 2 and 560 (Figure S1A). It appears that, although melanin is known to protect against oxidative stress [34], under the investigated strong stress conditions this protective pathway is inactive. However, a strikingly similar regulation of 
TABLE 2. GO enrichment analysis of transcriptome data of juvenile PQ-stressed $P$. anserina showing differential expression.

\begin{tabular}{|c|c|c|c|c|c|}
\hline \multicolumn{6}{|c|}{ Up-regulated } \\
\hline \multirow[t]{13}{*}{ CC } & GO:0044429 & $4.08 \mathrm{E}-22$ & 101 & 581 & mitochondrial part \\
\hline & GO:0005739 & $8.68 \mathrm{E}-19$ & 144 & 1121 & mitochondrion \\
\hline & GO:0005743 & $5.39 \mathrm{E}-17$ & 57 & 261 & mitochondrial inner membrane \\
\hline & GO:0019866 & $2.34 \mathrm{E}-16$ & 57 & 269 & organelle inner membrane \\
\hline & GO:0005740 & $2.15 \mathrm{E}-15$ & 71 & 408 & mitochondrial envelope \\
\hline & GO:0031966 & $2.06 \mathrm{E}-13$ & 65 & 386 & mitochondrial membrane \\
\hline & GO:0044455 & $6.74 \mathrm{E}-13$ & 38 & 159 & mitochondrial membrane part \\
\hline & GO:0005759 & $7.56 \mathrm{E}-12$ & 43 & 212 & mitochondrial matrix \\
\hline & GO:0031967 & $2.26 \mathrm{E}-09$ & 75 & 584 & organelle envelope \\
\hline & GO:0031975 & 4.99E-09 & 77 & 617 & envelope \\
\hline & GO:0005744 & $2.86 \mathrm{E}-07$ & 8 & 13 & mitochondrial inner membrane presequence translocase complex \\
\hline & GO:0005758 & $5.06 \mathrm{E}-06$ & 12 & 40 & mitochondrial intermembrane space \\
\hline & GO:0031305 & 4.79E-05 & 6 & 12 & integral to mitochondrial inner membrane \\
\hline \multirow[t]{20}{*}{ BP } & GO:0006839 & 1.97E-14 & 34 & 113 & mitochondrial transport \\
\hline & GO:0007005 & $2.31 \mathrm{E}-13$ & 50 & 243 & mitochondrion organization \\
\hline & GO:0006626 & $1.94 \mathrm{E}-09$ & 19 & 57 & protein targeting to mitochondrion \\
\hline & GO:0070585 & 3.75E-09 & 19 & 59 & protein localization to mitochondrion \\
\hline & GO:0009060 & $1.40 \mathrm{E}-07$ & 25 & 117 & aerobic respiration \\
\hline & GO:0030150 & 7.04E-07 & 9 & 18 & protein import into mitochondrial matrix \\
\hline & GO:0006744 & $1.61 \mathrm{E}-06$ & 8 & 15 & ubiquinone biosynthetic process \\
\hline & GO:0045333 & $4.81 \mathrm{E}-06$ & 33 & 215 & cellular respiration \\
\hline & GO:0065002 & 5.37E-06 & 11 & 33 & intracellular protein transmembrane transport \\
\hline & GO:0055114 & 8.04E-06 & 49 & 388 & oxidation-reduction process \\
\hline & GO:0032543 & 9.53E-06 & 15 & 62 & mitochondrial translation \\
\hline & GO:0017038 & $1.16 \mathrm{E}-05$ & 22 & 120 & protein import \\
\hline & GO:0015980 & $2.10 \mathrm{E}-05$ & 36 & 261 & energy derivation by oxidation of organic compounds \\
\hline & GO:0042180 & $2.10 \mathrm{E}-05$ & 81 & 781 & cellular ketone metabolic process \\
\hline & GO:0007007 & 3.87E-05 & 7 & 16 & inner mitochondrial membrane organization \\
\hline & GO:0006091 & $3.89 \mathrm{E}-05$ & 43 & 344 & generation of precursor metabolites and energy \\
\hline & GO:0044281 & 4.66E-05 & 130 & 1438 & small molecule metabolic process \\
\hline & GO:0006520 & 8.47E-05 & 59 & 541 & cellular amino acid metabolic process \\
\hline & GO:0000002 & $8.66 \mathrm{E}-05$ & 11 & 43 & mitochondrial genome maintenance \\
\hline & GO:0006627 & $9.41 \mathrm{E}-05$ & 4 & 5 & protein processing involved in protein targeting to mitochondrion \\
\hline \multirow[t]{3}{*}{ MF } & GO:0008320 & $7.45 \mathrm{E}-08$ & 11 & 23 & protein transmembrane transporter activity \\
\hline & GO:0015450 & $3.15 \mathrm{E}-07$ & 10 & 21 & P-P-bond-hydrolysis-driven protein transmembrane transporter activity \\
\hline & GO:0016491 & $8.58 \mathrm{E}-05$ & 166 & 1920 & oxidoreductase activity \\
\hline \multicolumn{6}{|c|}{ Down-regulated } \\
\hline \multirow[t]{7}{*}{ BP } & GO:0042438 & 4.97E-07 & 9 & 21 & melanin biosynthetic process \\
\hline & GO:0032787 & $6.47 \mathrm{E}-07$ & 32 & 236 & monocarboxylic acid metabolic process \\
\hline & GO:0006725 & 4.29E-06 & 28 & 209 & cellular aromatic compound metabolic process \\
\hline & GO:0006582 & $5.96 \mathrm{E}-06$ & 9 & 27 & melanin metabolic process \\
\hline & GO:0044550 & $8.58 \mathrm{E}-06$ & 10 & 35 & secondary metabolite biosynthetic process \\
\hline & GO:0019748 & 1.57E-05 & 11 & 45 & secondary metabolic process \\
\hline & GO:0006083 & $7.08 \mathrm{E}-05$ & 6 & 15 & acetate metabolic process \\
\hline \multirow[t]{18}{*}{ MF } & GO:0016491 & $8.73 E-17$ & 193 & 1920 & oxidoreductase activity \\
\hline & GO:0004497 & $5.16 \mathrm{E}-11$ & 49 & 298 & monooxygenase activity \\
\hline & GO:0004312 & $2.80 \mathrm{E}-07$ & 16 & 60 & fatty acid synthase activity \\
\hline & GO:0016705 & $2.82 \mathrm{E}-07$ & 54 & 442 & oxidoreductase activity, acting on paired donors, with incorporation or reduction of ... \\
\hline & GO:0005506 & $3.36 \mathrm{E}-07$ & 58 & 492 & iron ion binding \\
\hline & GO:0016701 & 1.99E-06 & 23 & 129 & oxidoreductase activity, acting on single donors with incorporation of molecular oxygen \\
\hline & GO:0020037 & 2.54E-06 & 45 & 366 & heme binding \\
\hline & GO:0046906 & $2.95 \mathrm{E}-06$ & 45 & 368 & tetrapyrrole binding \\
\hline & GO:0046872 & 7.29E-06 & 201 & 2627 & metal ion binding \\
\hline & GO:0004316 & 7.77E-06 & 10 & 31 & 3-oxoacyl-[acyl-carrier-protein] reductase (NADPH) activity \\
\hline & GO:0046914 & $8.28 \mathrm{E}-06$ & 162 & 2022 & transition metal ion binding \\
\hline & GO:0009055 & $2.14 \mathrm{E}-05$ & 46 & 409 & electron carrier activity \\
\hline & GO:0043169 & $2.32 \mathrm{E}-05$ & 208 & 2781 & cation binding \\
\hline & GO:0016614 & $3.58 \mathrm{E}-05$ & 51 & 480 & oxidoreductase activity, acting on $\mathrm{CH}-\mathrm{OH}$ group of donors \\
\hline & GO:0070330 & 4.41E-05 & 10 & 37 & aromatase activity \\
\hline & GO:0016616 & $5.28 \mathrm{E}-05$ & 44 & 399 & oxidoreductase activity, acting on the $\mathrm{CH}-\mathrm{OH}$ group of donors, NAD or NADP as acceptor \\
\hline & GO:0016702 & $6.01 E-05$ & 19 & 117 & oxidoreductase activity, acting on single donors with incorporation of molecular oxygen... \\
\hline & GO:0008709 & $7.86 \mathrm{E}-05$ & 5 & 9 & cholate 7-alpha-dehydrogenase activity \\
\hline
\end{tabular}

All differentially expressed genes (Factor $<3 ; \mathrm{pV}<0.01$ ) were analyzed. GO terms with $\mathrm{pV}<1 \mathrm{E}-5$ are shown. The GO terms referred to in the text are highlighted in red. CC: Cellular Component; BP: Biological Process; C: Count (number of genes of respective GO Term in the group (up- or down-regulated)); S: Size (total number of $P$. anserina genes with the respective $\mathrm{GO}$ term). 
these transcripts in the copper-depleted grisea mutant points towards a copper-dependent regulation of these genes, which will later be further discussed.

Among the most enriched molecular functions in the group of down-regulated genes are the GO terms 'fatty acid synthase activity', 'oxidoreductase activity' and 'monooxygenase activity' (Table 2). The synthesis of fatty acids is also an energy consuming process. Similar to our data, genes involved in fatty acid metabolism are downregulated in PQ-stressed Drosophila melanogaster but not in aged flies [35]. The GO term 'oxidoreductase activity' is among the enriched terms in both, up- and downregulated transcripts. Referring to the $\mathrm{H}_{2} \mathrm{O}_{2}$-release (Figure 1 ), the generation of superoxide can be expected to have a strong effect on the redox status of the cell, which in turn seems to have an effect on regulation of enzymes with redox activity.

Next, we compared GO term enrichments of the current study with those of a previous analysis in which individuals were aged under standard growth conditions [19]. One possibility leading to the same GO terms in the up- or down-regulated fraction of genes with a comparable $\mathrm{p}$ value in our GO-term enrichment analysis is a similar gene regulation during aging and $P Q$-stress. If this is true, this would support a ROS-dependent regulation during aging. Such similarities can be observed for the up-regulation of genes with the GO term 'mitochondrial part' (GO: 0044429) and for the regulation of transcripts coding for proteins of the respiratory chain (GO:0005746;
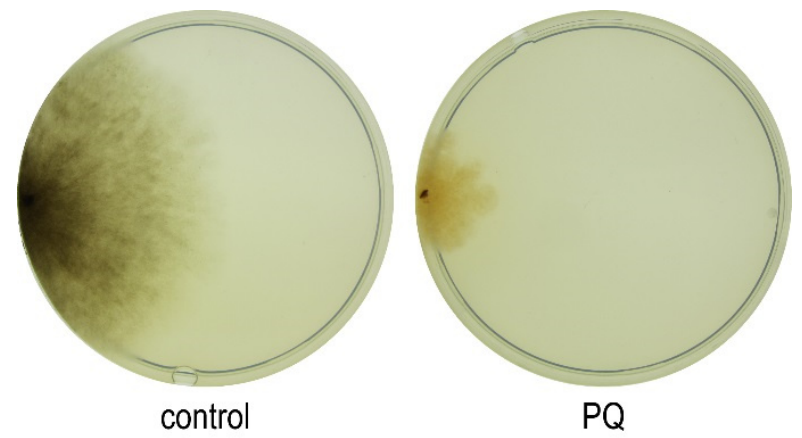

FIGURE 3: Effect of PQ-stress on the phenotype of $\boldsymbol{P}$. anserina. Cultures of the wild type grown for 8 days on $P Q$-free CM medium or on CM medium supplemented with $200 \mu \mathrm{M} P Q$.

GO:0070469; GO:0045333) (Table 3). Transcripts coding for the proteasome and its assembly (GO:0000502; GO:0031597; GO:0043248) and for ribosomes (GO:0022626; GO:0044391; GO:0005840; G00015935; GO:0022625; GO:0015934) are enriched in the downregulated groups during both, aging and $\mathrm{PQ}$-stress, except for the GO term 'ribosomal subunit' (GO:0044391), which refers to mitochondrial ribosomes and is up-regulated during PQ-stress.

During aging of $P$. anserina we previously reported an enrichment of autophagy genes in a group of continuously up-regulated genes [19]. In the current study, we did not

TABLE 3. Comparison of enriched GO terms in the data set of PQ-stressed $P$. anserina cultures with those from an earlier longitudinal aging study [19].

\begin{tabular}{|c|c|c|c|c|c|c|c|c|c|}
\hline \multirow{2}{*}{$\begin{array}{c}\text { Aging } \\
\text { GO term }\end{array}$} & \multirow[b]{2}{*}{ p-value } & \multirow[b]{2}{*}{ C } & \multirow[b]{2}{*}{$\mathbf{S}$} & \multirow[b]{2}{*}{ Term } & \multirow[b]{2}{*}{ Direction } & \multicolumn{2}{|c|}{ juv PQ up } & \multicolumn{2}{|c|}{ juv $P Q$ down } \\
\hline & & & & & & $p$-value & C & p-value & C \\
\hline 44429 & $7.5 \mathrm{E}-03$ & 152 & 581 & mitochondrial part & up & $1.03 E-63$ & 318 & & \\
\hline 44429 & $9.3 \mathrm{E}-06$ & 171 & 581 & mitochondrial part & down & & & & \\
\hline 5746 & $5.2 \mathrm{E}-03$ & 23 & 62 & mitochondrial respiratory chain & down & & & & \\
\hline 5746 & $2.1 \mathrm{E}-03$ & 24 & 62 & mitochondrial respiratory chain & up & $9.08 \mathrm{E}-18$ & 47 & & \\
\hline 70469 & $3.9 \mathrm{E}-03$ & 27 & 75 & respiratory chain & up & 7.27E-16 & 51 & & \\
\hline 45333 & $2.4 \mathrm{E}-03$ & 65 & 215 & cellular respiration & up & $1.09 \mathrm{E}-22$ & 117 & & \\
\hline 45333 & $4.1 \mathrm{E}-04$ & 68 & 215 & cellular respiration & down & & & & \\
\hline 502 & 1.7E-04 & 35 & 89 & proteasome complex & down & & & $5.75 \mathrm{E}-03$ & 28 \\
\hline 31597 & $1.6 \mathrm{E}-03$ & 13 & 26 & cytosolic proteasome complex & down & & & $2.08 \mathrm{E}-03$ & 12 \\
\hline 34515 & $1.6 \mathrm{E}-03$ & 13 & 26 & proteasome storage granule & down & & & $2.08 \mathrm{E}-03$ & 12 \\
\hline 43248 & $1.3 \mathrm{E}-03$ & 12 & 23 & proteasome assembly & down & & & 7.83E-03 & 10 \\
\hline 22626 & $3.5 \mathrm{E}-11$ & 50 & 94 & cytosolic ribosome & down & & & $3.75 \mathrm{E}-11$ & 47 \\
\hline 5840 & $2.2 \mathrm{E}-08$ & 126 & 367 & ribosome & down & & & 8.66E-04 & 97 \\
\hline 22627 & $6.7 \mathrm{E}-07$ & 23 & 39 & cytosolic small ribosomal subunit & down & & & $2.25 \mathrm{E}-06$ & 21 \\
\hline 15935 & $6.9 \mathrm{E}-07$ & 30 & 58 & small ribosomal subunit & down & & & $1.00 \mathrm{E}-03$ & 22 \\
\hline 22625 & $2.9 \mathrm{E}-05$ & 23 & 46 & cytosolic large ribosomal subunit & down & & & $9.10 \mathrm{E}-07$ & 24 \\
\hline 15934 & $4.2 \mathrm{E}-05$ & 35 & 84 & large ribosomal subunit & down & & & 4.44E-04 & 30 \\
\hline 44391 & 3.1E-09 & 61 & 137 & ribosomal subunit & down & 1.47E-09 & 65 & & \\
\hline 6090 & $2.2 \mathrm{E}-05$ & 18 & 32 & pyruvate metabolic process & down & & & & \\
\hline
\end{tabular}

Terms that are enriched in the same group (up- or down-regulated) during aging and PQ-stress are highlighted in green. Similar GO terms are grouped. CC: Cellular Component; BP: Biological Process; C: Count (number of genes of respective GO Term in the group (up- or down-regulated)); S: Size (total number of $P$. anserina genes with the respective $\mathrm{GO}$ term). 
find such an increase in abundance of autophagy transcripts during PQ-stress of juvenile $P$. anserina. In contrast, $P Q$-stress applied on senescent cultures resulted in the enrichment of GO terms of the categories 'positive regulation of autophagy' (GO: 0010508) and 'regulation of autophagy' (GO: 0010506) in the group of up-regulated genes (Table S1). These results seem to indicate that a regulation of the corresponding genes is ROS-dependent but requires additional factors and/or conditions as they accumulate in senescent cultures.

\section{ROS scavenging pathways}

In $P$. anserina different pathways affecting oxidative stress are known to affect aging and longevity. Among these, ROS scavenging pathways are effective via enzymatic detoxification. In the genome of $P$. anserina a number of ROS scavenging enzymes is encoded. We investigated whether the corresponding genes are transcriptionally regulated after applying $P Q$-stress and during aging of cultures without $P Q$-stress. As indicated in Figure $4 A$, transcripts of PaCcp1, PaCatB, and PaTrx3 are up-regulated after applying PQ-stress. PaCcp1, the gene coding for cytochrome $c$ peroxidase, which is located in the mitochondrial inter- membrane space, catalyzes the detoxification of $\mathrm{H}_{2} \mathrm{O}_{2}$ to water by oxidation of ferrocytochrome $c$. After application of PQ-stress, transcript levels increase by factors of 6.36 to 11.96 in juvenile and senescent cultures (Figure 4A). In contrast, decreased levels of this transcript are found during aging when juvenile and old cultures are compared. The only transcript that is up-regulated during aging and after PQ-stress is the transcript of PaCatB coding for a $P$. anserina catalase. Among the down-regulated transcripts, the PaSod2 transcript is most effected during both, aging and PQ-stress. The gene encoding the $\mathrm{Cu} / \mathrm{Zn}-\mathrm{SOD}$ (PaSOD1) is only slightly up-regulated during aging. Administration of PQ-stress leads to a reduction of PaSod1 transcript levels. This reduction increases with the age of the investigated culture.

To test whether the identified up- and down-regulation of PaSod1 and PaCatB contributes to SOD and CATactivities, respectively, we determined the overall SOD activity and the $\mathrm{H}_{2} \mathrm{O}_{2}$ decomposition activity of different $P$. anserina strains. SOD activity is significantly reduced during aging (Figure 4B). The observed decrease in juvenile cultures challenged with $\mathrm{PQ}$-stress is consistent with the transcript data for PaSod1 and PaSod2. This is not the case
A

\begin{tabular}{ll|rrrr} 
gene & PaNo. & juv $\mathrm{PQ}$ & $\mathrm{ma} \mathrm{PQ}$ & \multicolumn{3}{c}{ sen PQ aging } \\
\hline PaCcp1 & Pa_1_6960 & 6.36 & 5.78 & 11.96 & 0.65 \\
PaCatB & Pa_7_1610 & 3.92 & 2.43 & 2.85 & 2.93 \\
PaTrx3 & Pa_7_210 & 3.41 & 3.76 & 8.63 & 0.73 \\
PaSod4 & Pa_1_10620 & 1.95 & 1.85 & 0.66 & 0.97 \\
prx5-like Prx & Pa_1_14500 & 1.91 & 0.70 & 4.29 & 0.97 \\
PaCatA & Pa_7_4240 & 1.47 & 0.37 & 0.98 & 0.17 \\
PaSod3 & Pa_5_1740 & 1.16 & 0.78 & 1.06 & 0.61 \\
PaPrx1 & Pa_5_8240 & 1.13 & 0.71 & 0.62 & 1.41 \\
PaTrx4 & Pa_5_10350 & 1.02 & 1.02 & 0.43 & 2.94 \\
PaSod1 & Pa_1_17400 & 0.82 & 0.61 & 0.31 & 1.27 \\
PaTrx5 & Pa_1_15440 & 0.71 & 0.67 & 0.16 & 1.18 \\
PaCat2 & Pa_6_11240 & 0.69 & 0.84 & 0.97 & 0.82 \\
Gluth. Perox. Pa_2_8460 & 0.64 & 0.85 & 0.72 & 0.44 \\
Put.Prx & Pa_5_4690 & 0.51 & 0.60 & 1.25 & 0.46 \\
PaTrx1 & Pa_7_1190 & 0.48 & 0.69 & 1.54 & 0.25 \\
PaTrx2 & Pa_6_8740 & 0.39 & 0.66 & 0.74 & 0.18 \\
Put.Perox. & Pa_2_10 & 0.37 & 3.84 & 1.65 & 0.43 \\
PaSod2 & Pa_2_4460 & 0.08 & 0.23 & 0.23 & 0.18 \\
& & & & &
\end{tabular}

B
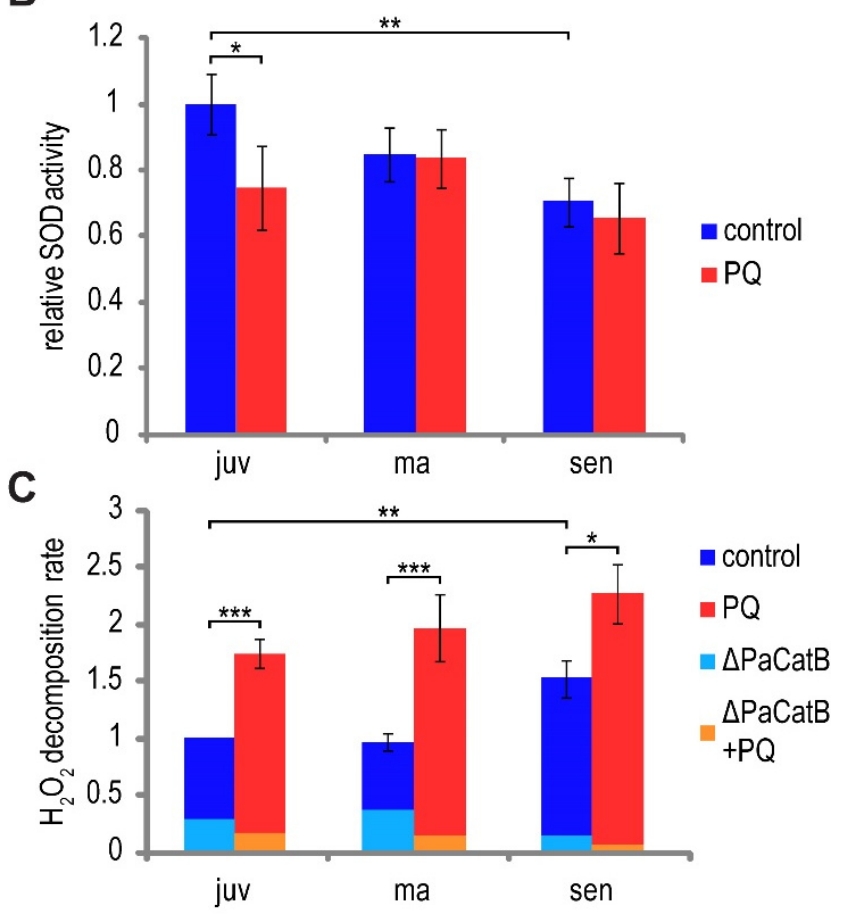

FIGURE 4: Effect of PQ-stress and aging on ROS-scavenging pathways. (A) Transcriptome data of ROS scavenger enzymes. Colors and numbers indicate relative expression of transcripts of the indicated genes and treatment. Relative expression was calculated by dividing tpm of juvenile PQ-stressed samples by tpm of juvenile control (juv PQ), middle-aged PQ-stressed samples by middle-aged control (ma PQ), senescent $\mathrm{PQ}$-stressed samples by senescent control (sen $\mathrm{PQ}$ ) and senescent control by juvenile control (aging). (B,C) The overall SOD activity and $\mathrm{H}_{2} \mathrm{O}_{2}$ decomposition rate were measured in protein extracts of juvenile (juv), middle-aged (ma) and senescent (sen) $P$. anserina cultures grown in PQ-free medium or in medium supplemented with $200 \mu \mathrm{M} P Q$. (B) Overall SOD activity is shown as mean relative expression to the juvenile wild type \pm standard error. $n=6$. Student's t test $p$-values: juv to juv $P Q p V=0.049$; juv to sen $p V=0.007$. (C) Besides in wild-type strains (control and $\mathrm{PQ}$ ), measurement of $\mathrm{H}_{2} \mathrm{O}_{2}$ decomposition was carried out in a $\triangle P a C a t B$ strain to estimate the portion of activity related to PaCATB. Data of wild type is shown as mean \pm standard error. $n=9$ - 11 for wt; $n=1$ for $\triangle$ PaCatB. Student's t-test $p$-values of wild type: juv to sen $\mathrm{pV}=0.004$; juv to juv $\mathrm{PQ} p V=7.05 \mathrm{E}-5$; ma to $\mathrm{ma} P Q \mathrm{pV}=2.41 \mathrm{E}-5$; sen to sen $\mathrm{PQ} \mathrm{pV}=0.016$. 
when middle-aged and senescent cultures are analyzed. In these age stages SOD activity is unchanged, although the transcripts of PaSod1 and PaSod 2 are less abundant, indicating that there are other factors affecting SOD activity in these age stages.

Catalase activity in cell extracts of the wild type and the PaCatB deletion strain [36] was investigated in vitro by photometric determination of $\mathrm{H}_{2} \mathrm{O}_{2}$ decomposition. The analysis of the PaCatB deletion strain verifies that the major activity measured with this method, under the tested conditions, is PaCATB activity (Figure $4 C$ ). In the wild type, the increase of $P a C a t B$ transcripts during aging and $P Q$ stress observed in transcriptome data (Figure $4 A$ ) is reflected by increased PaCATB activity (Figure 4C), indicating a transcriptional regulation of this protein. It appears that $P a C a t B$ is induced by superoxide during aging and oxidative stress.

Carotenoids are organic pigments with antioxidant activity [37]. Previously we have shown that a high level of $\beta$ carotene and other carotenoids increases the lifespan of $P$. anserina [38]. PaAL-1 and PaAL-2 are the rate limiting enzymes of the carotenoid biosynthesis. We found that, at least in juvenile cultures, PQ-stress leads to a clear increase in transcript levels by factors 6.15 and 5.88 , respectively (Figure S1B). Also, PaAL-3 levels, coding for another component of the carotenoid biosynthesis pathway is increased after PQ-stress of juvenile $P$. anserina by a factor of 2.04. In older cultures the increase in transcript levels is not that clear. For PaAl-2 and PaAl-3 transcript levels do even decrease after $P Q$-stress. It appears that, at least in earlier stages of the life cycle, carotenoid biosynthesis is induced to counteract oxidative stress.

\section{PQ-stress induces a strong response on copper and iron metabolism}

In previous work, a strong link between oxidative stress, aging and a stringent control of copper homeostasis has been established in $P$. anserina [12, 14, 22, 39-41]. This link was unraveled by the analysis of wild-type strains of different age and of the long-lived grisea mutant. During aging of the wild type, transcript levels of the copper-regulated genes become altered. While transcripts coding for the $P$. anserina metallothionein (PaMT1) are increased, those coding for a high affinity copper transporter (PaCTR3) and for PaSOD2 are reduced. Consistently, PaSOD2 activity is reduced in old cultures $[12,42]$. In addition, PaSOD1 activity, which is depending on the availability of cytoplasmic copper, is higher in wild-type strains of old age [12]. Copper measurement by total reflection X-ray spectroscopy delineated the reason for these changes as an age-related increase of cytoplasmic copper levels [43]. Copperregulated transcription was demonstrated to be controlled by the copper-sensing transcription factor GRISEA. In senescent cultures, due to high cytoplasmic copper levels, GRISEA is inactivated and thus the expression of target genes is blocked. The same holds true in a Grisea loss-offunction mutant. Since transcription of PaCtr3, coding for a high affinity copper transporter, is dependent on the availability and activity of GRISEA, both in senescent wild-type strains as well as in the grisea mutant, copper-uptake is only possible via low affinity import. As a consequence, a switch from a copper-dependent standard to an irondependent alternative respiration, a strongly reduced generation of the mitochondrial superoxide anion and pronounced changes in gene expression are observed in the mutant $[22,23,41]$.

The current analyses, in which we aimed to exaggerate superoxide stress via the application of $P Q$, indeed revealed a strong response of $P Q$-stress on gene expression linked to copper homeostasis. Genes either regulated by copper via yet unidentified transcription factors, or via the activity of GRISEA turned out to be down-regulated as occurs during aging or in the GRISEA deficiency mutant (Figure 5A). One exception is the regulation of PaCtr3, which at first glance seems to be regulated in middle-aged and senescent cultures stressed with $P Q$ in the opposite direction as during wild type aging and in the grisea mutant. However, while the transcript numbers in the different samples, including the PaCtr3 mRNA in the untreated juvenile wildtype strain was in the range of 50 to 3,500 transcripts per million (tpm), transcript levels of PaCtr3 in middle-aged untreated wild-type strains dramatically dropped to about 1 to $2 \mathrm{tpm}$. As demonstrated earlier, this is the result of increases in cytoplasmic copper leading to the repression of GRISEA activity [43]. Because of this low expression of PaCtr3, we used qRT-PCR to verify the transcriptome data of this gene and of several other genes involved in copper homeostasis (Figure 5B). In order to obtain more accurate results, we used the two reference genes PaPorin, coding for a mitochondrial outer membrane protein and PaRp/19, coding for a subunit of the 605 ribosome. PaPorin is an established reference gene for qRT-PCR in $P$. anserina. Since the transcript abundance was found to vary during PQ-stress (307 to $1,307 \mathrm{tpm}$ ), we additionally included PaRpl19, which is stably and highly (1,031 to $1,183 \mathrm{tpm})$ expressed during aging and $\mathrm{PQ}$-stress. The expression profiles of the investigated genes PaAox, PaSod2, PaCtr1 and PaCtr2 were basically verified by qRT-PCR experiments (Figure 5B). The down-regulation of PaCtr3 transcripts during aging, as found in the Super-SAGE analysis, was also verified by qRT-PCR. However, the up-regulation of PaCtr3 by $P Q$-stress in middle-aged and senescent cultures is weaker in qRT-PCR than in the transcriptome data. The overall transcript abundance of PaCtr3 in aged hyphae is probably so small that minor fluctuations in transcripts levels lead to strong effects on the relative transcript abundance, which however appear not to be of biological relevance. We assume that PaCtr3 is only expressed in juvenile cultures in significant amounts and that transcription of this gene is silenced during aging and by $P Q$ treatment. Taken together, the data reveal a PQ-induced downregulation of genes involved in the control of cellular copper homeostasis.

This conclusion is confirmed by an up-regulation of transcripts coding for the alternative oxidase PaAox during $\mathrm{PQ}$-stress. In order to verify that this up-regulation is reflected by a switch from a copper-dependent respiration 
A

\begin{tabular}{|c|c|c|c|c|c|c|}
\hline gene & PaNo. & juv $P Q$ & $\mathrm{maPQ}$ & $\operatorname{sen} P Q$ & aging & grisea \\
\hline \multirow[t]{2}{*}{ PaAox } & Pa_3_1710 & 7.72 & 3.60 & 12.09 & 1.77 & $7 \quad 19.81$ \\
\hline & Pa_2_7310 & 0.03 & 0.02 & 0.01 & 0.63 & 0.01 \\
\hline PaSod2 & Pa_2_4460 & 0.08 & 0.23 & 0.23 & 0.18 & 0.98 \\
\hline \multirow[t]{2}{*}{ PaFre1 } & Pa_5_11970 & 0.05 & 0.13 & 0.22 & 0.39 & 0.00 \\
\hline & Pa_6_10000 & 0.03 & 0.05 & 0.08 & 0.59 & 0.08 \\
\hline PaCtr1 & Pa_1_16400 & 0.42 & 0.75 & 0.75 & 0.98 & 0.10 \\
\hline PaCtr2 & $\mathrm{Pa}$ _4_4770 & 0.02 & 0.19 & 0.23 & 0.24 & 0.06 \\
\hline PaCtr3 & Pa_3_10440 & 0.28 & 5.01 & 6.45 & 0.04 & $0.0^{\circ}$ \\
\hline PaMth1 & Pa_2_7880 & 0.15 & 0.03 & 0.69 & 0.38 & 0.06 \\
\hline
\end{tabular}

B
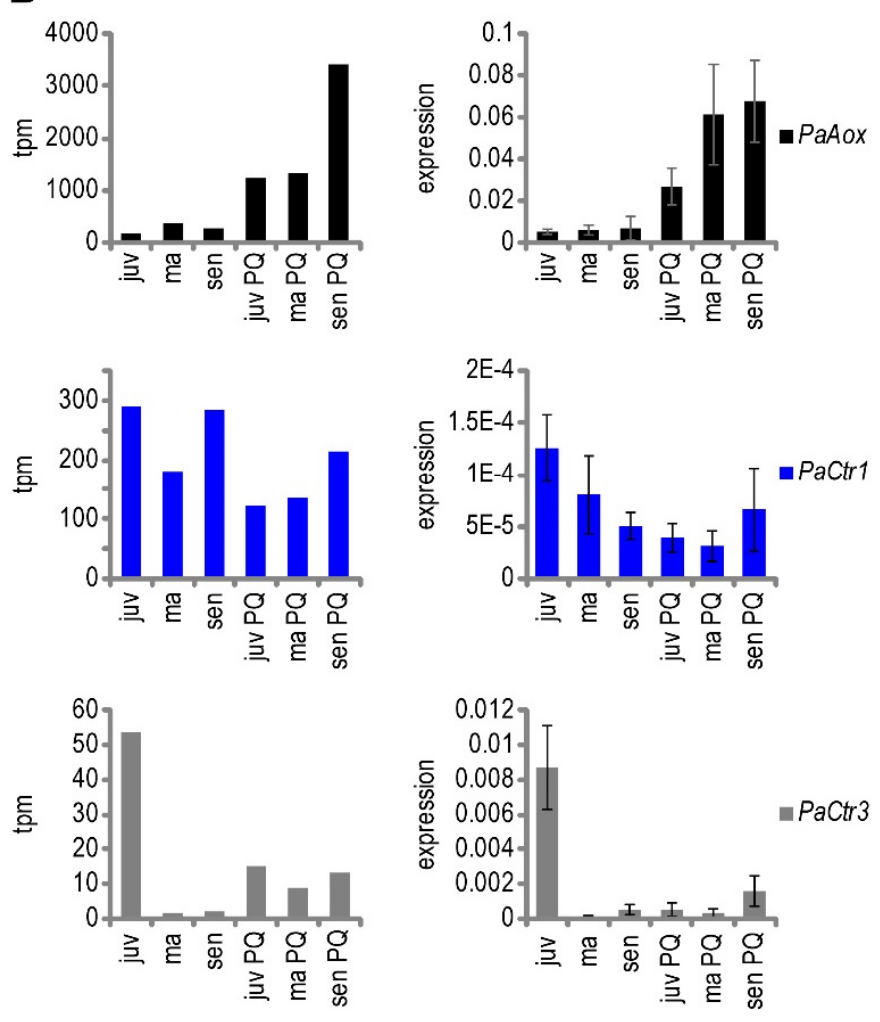

C
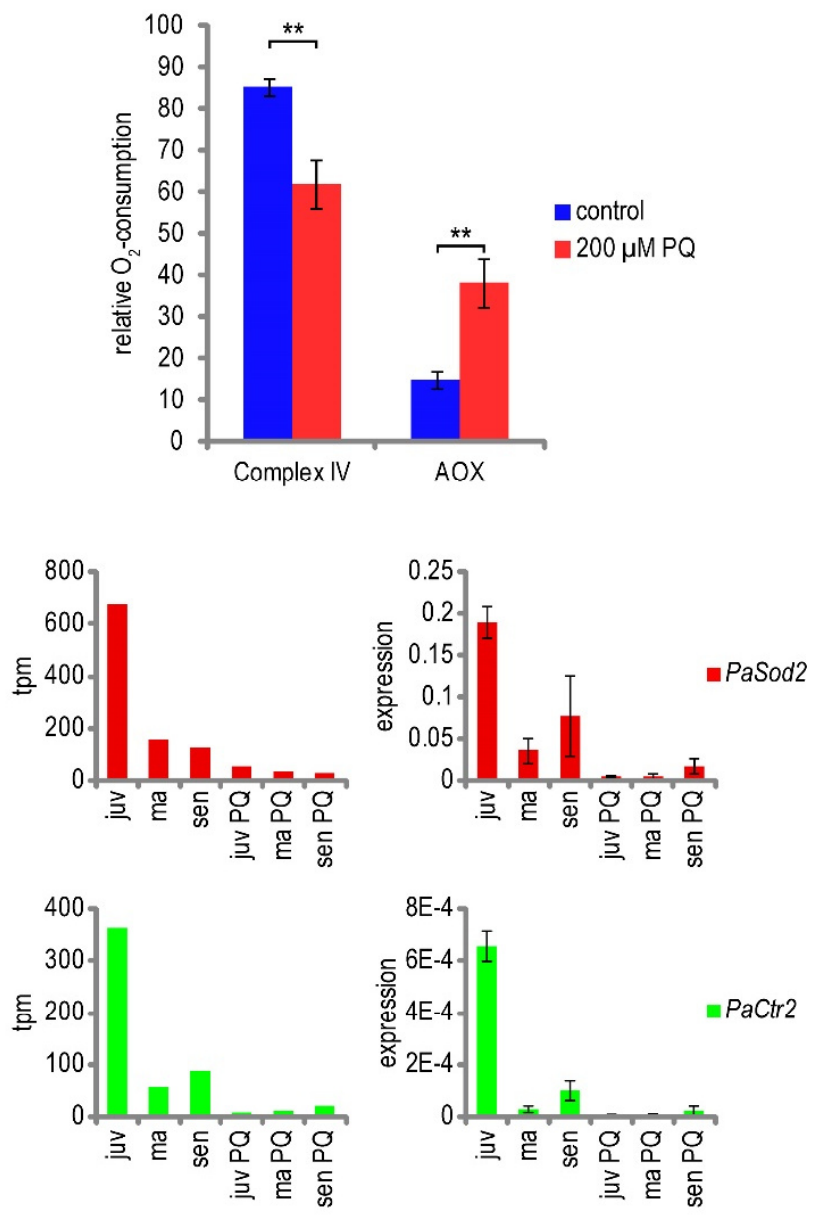

FIGURE 5: Effect of PQ-stress on the regulation of copper controlled genes. (A) Transcriptome data of copper and GRISEA regulated proteins. Colors and numbers indicate relative expression of transcripts of the indicated genes. Relative expression was calculated by dividing tpm of juvenile PQ-stressed samples by tpm of juvenile control (juv PQ), middle-aged PQ-stressed samples by middle-aged control (ma PQ), senescent PQ-stressed samples by senescent control (sen PQ), senescent control by juvenile control (aging) and grisea by wild-type control (grisea). (B) Verification of transcriptome data of the selected genes PaAox, PaSod2, PaCtr1, PaCtr2, and PaCtr3. Results from SuperSAGE analysis are shown in tpm (tags per million). The results of the corresponding qRT-PCR are depicted as relative expression levels to the reference genes PaPorin and PaRp/19. Data are displayed as mean \pm standard error. $\mathrm{n}=3$. (C) Measurement of complex IV and PaAOX activity in control and $\mathrm{PQ}$-stressed mycelia. Juvenile $P$. anserina was grown as described for transcriptome analysis. The oxygen consumption of 2 to 9 mg mycelium was measured in a high resolution respirometer. To determine the percentage of complex IV and PaAOX dependent respiration, a final concentration of $4 \mathrm{mM} \mathrm{SHAM}$ and $1 \mathrm{mM} \mathrm{KCN}$ was used to inhibit PaAOX and complex IV, respectively. Bars are mean \pm standard error of 6 - 7 experiments with two different cultures. $n=20$. Student's t-test: $p V=0.0019$. 
via cytochrome $c$ oxidase to an alternative respiration, as it is found in the copper-depletion mutant grisea, we determined the respiratory activity of complex IV and of PaAOX. Juvenile $P$. anserina were grown similar to the strains investigated in the transcriptome analysis. Oxygen consumption by complex IV or PaAOX was measured after inhibition of one of the two complexes revealing a significant reduction in cytochrome $c$-dependent respiration and an increase of AOX-dependent respiration from $15 \%$ to $39 \%$ in $\mathrm{PQ}$-stressed strains (Figure $5 \mathrm{C}$ ). PaAOX utilizes iron as cofactor. Iron-uptake in fungi takes place via two basic pathways [44]. The first one, the reductive iron assimilation (RIA) pathway, is depending on the reduction of ferric iron to ferrous iron via the FRE1 reductase [45]. Strikingly, during $P Q$-stress, aging, and in the grisea mutant, transcript level of the gene coding for the best $P$. anserina homolog of FRE1 (Pa_5_11970) is strongly reduced (Figure S1C). In yeast, uptake of $\mathrm{Fe}^{2+}$ is controlled by the iron transporter ScFTR1 and the copper oxidase ScFET3. The ScFtr1 homo$\log \mathrm{Pa}$ _6_4210 is not consistently regulated during PQstress. The three best $P$. anserina homologs of ScFET3 are encoded by Pa_6_4220, Pa_6_2250 and Pa_2_530. They are down-regulated during $P Q$-stress by factors $0.12-0.44$ (Figure S1C) suggesting that RIA is impaired after PQ-stress. Under these conditions, like concluded for the grisea mutant, another iron-uptake system appears to be active. This pathway utilizes small iron binding proteins, termed siderophores. These molecules are secreted from the mycelium by a special siderophore transporter to bind extracellular iron and are subsequently transported back into the fungus and degraded to release iron for cellular use [46]. Putative homologs to this iron transport system in Aspergillus spec have been identified in P. anserina by in silico analysis [23]. The Aspergillus fumigatus proteins AfSIDA, AfSIDF and AfSIDD are necessary to produce the siderophore fusarin C. Genes of $P$. anserina coding for proteins with the highest degree of homology to these proteins (Pa_4_4430, Pa_5_4760 and Pa_3_11200) are up-regulated by factors between 2.04 and 5.09 during PQ-stress (Figure S1D). In Aspergillus the gene AfSidC is additionally needed for the synthesis of the intracellular siderophore ferricrocin. The gene coding for the best $P$. anserina homolog of AfSidC, $\mathrm{Pa} 4$ 44440, is up-regulated by factor 1.66 to 2.11 during $P Q$-stress. However, there are additional homologs with very high identity to AfSIDC. Furthermore, the genes coding for the putative homologs of the $A$. nidulans siderophore transporters MirB and MirC are mostly up-regulated during PQ-stress (Figure S2D). Overall, consistent with the observed impairment of copper-uptake, iron-uptake via siderophores appears to be induced during PQ-stress in $P$. anserina, although one has to keep in mind that this conclusion is only based on the homology to Aspergillus secondary metabolism genes. An increased iron influx would promote alternative respiration via iron dependant $A O X$ in stressed cells with impairment in standard cytochrome $c$ dependent respiration.

In previous investigations, it has been shown that excess copper has negative effects on $P$. anserina and that copper transport is tightly regulated [43]. It is reasonable to assume that the addition of $P Q$ influences the balance between the essential and the negative role of copper on the organism. To test this assumption we investigated the lifespan of $P$. anserina on medium supplemented with $\mathrm{PQ}$ and copper. Although the gene coding for high affinity copper transport is down-regulated during PQ-stress, copper can be transported into the cell by low affinity copper transport, if the copper concentration in the surrounding medium is high enough. To determine the lifespan under copper- and PQ-stress, mycelial pieces from cultures developed from ascospores after germination on sporulation medium were transferred to $\mathrm{M} 2$ medium supplemented with $\mathrm{CuSO}_{4}$ and $\mathrm{PQ}$. The addition of low concentrations of $P Q$ has a strong lifespan extending effect most likely reflecting a hormetic response [30]. In contrast, addition of $100 \mu \mathrm{M} \mathrm{CuSO}{ }_{4}$ or $100 \mu \mathrm{M}$ PQ leads to decreased lifespans. Addition of one stressor alone results in a decrease of the median lifespan of 27 days (non-stressed cultures) to 21.5 days in copper supplemented medium and to 21.6 days in $\mathrm{PQ}$ containing medium (Figure $6 \mathrm{~A}$ ). Most strikingly, the addition of both, $100 \mu \mathrm{M} \mathrm{PQ}$ and $100 \mu \mathrm{M} \mathrm{CuSO}_{4}$ has a synergistic effect: cultures die very fast and have a median lifespan of 3.8 days. Consistent results were obtained for the effect of the two stressors on the growth rate. Strains challenged with either exogenous $\mathrm{PQ}$ or copper sulfate are characterized by reduced growth rates (Figure 6B). The simultaneous addition of copper sulfate and $P Q$ to the medium leads to a complete growth arrest after one to two days, possibly caused by a synergistic effect of the two different stressors as the result of an increase of cytoplasmic copper beyond lethal thresholds.

Finally, we investigated the effect of copper depletion on global gene expression. We compared the differentially expressed genes (factor $<3$; pV $<0.01$ ) of the copper depletion mutant grisea [23] with the differentially expressed genes in juvenile $P Q$-stressed fungi and found 167 upregulated and 267 down-regulated genes affected in both situations (Figure $6 \mathrm{C}$ ). These numbers are much higher than statistically expected if regulations were random (Table 1). Moreover, statistical analysis revealed a higher similarity of transcript regulation in the grisea mutant and PQstressed juvenile wild type (odds ratio 6.29 / 8.41) than during aging and by PQ-treatement (odds ratio 3.19 / 3.21) (Table 1). We conclude that PQ-stress has a strong effect on copper homeostasis and therefore on copperdependent gene expression.

\section{PQ-stress induced mitochondrial remodeling and the induction of programmed cell death}

The current genome-wide transcriptome analysis revealed a strong effect of oxidative stress induced by $P Q$ on gene expression. We observed a striking up-regulation of genes involved in mitochondrial remodeling which is expected, since $P Q$ is active in ROS generation at the mitochondrial respiration chain. It appears that $P Q$-stress is indeed a good mimetic to induce mitochondrial ROS-stress as it naturally occurs during aging of biological systems. The effect of $\mathrm{PQ}$-stress on cellular metal homeostasis verifies earlier conclusions of age-related increases in cytoplasmic copper 
levels. Such changes have been reported to occur during normal aging of the $P$. anserina wild type. The source of accumulating cytoplasmic copper has been suggested to be the mitochondrion $[12,41,43]$ which is known to be a cellular copper store $[47,48]$, but, although experimentally not addressed in $P$. anserina so far, copper release from the vacuole may also contribute to the age-related increase in cytoplasmic copper $[49,50]$. A release of copper from mitochondria during aging of $P$. anserina appears to result from changes in mitochondrial membrane permeability [14]. The age-related accumulation of cyclophilin D (PaCYPD), a component and regulator of the mitochondrial permeability transition pore, in the $P$. anserina wild type during aging [51] supports this conclusion and identifies a specific type of membrane permeabilization (for a review:
[52]). Previous work demonstrating that the overexpression of $P a C y p D$, coding for cyclophilin $D$, accelerates aging via the induction of programmed cell death is further support of such a mechanism which is linked to pronounced mitochondrial membrane remodeling and the rupture of the outer mitochondrial membrane [21, 53, 54]. The processes identified in the microbial model system $P$. anserina can explain the increase in cytoplasmic copper and the effect on copper-regulated gene expression as it has been described to occur during replicative senescence of human fibroblasts [43]. They thus may be part of mechanisms involved in the control of programmed cell death and aging which are conserved from yeast to humans [43, 55].
A

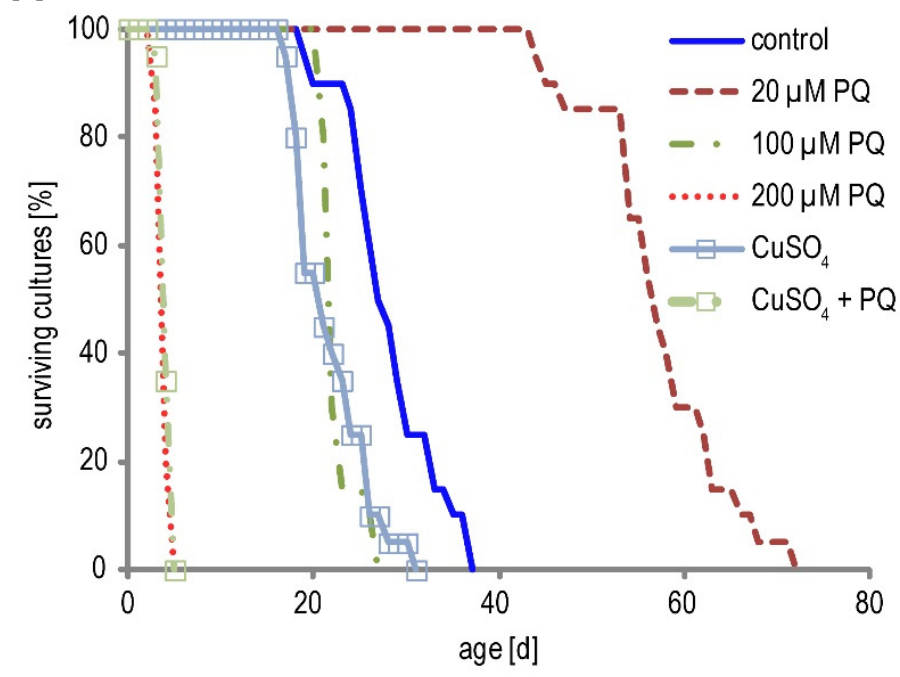

B

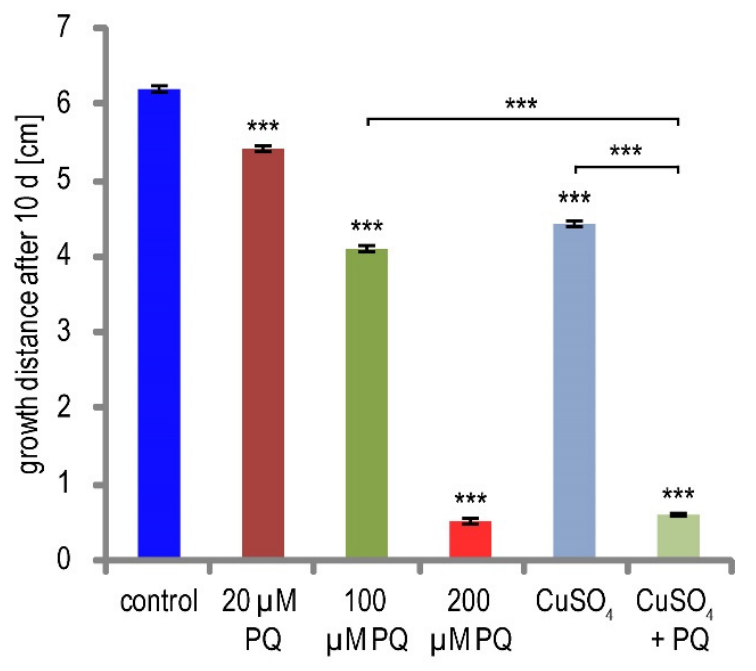

C

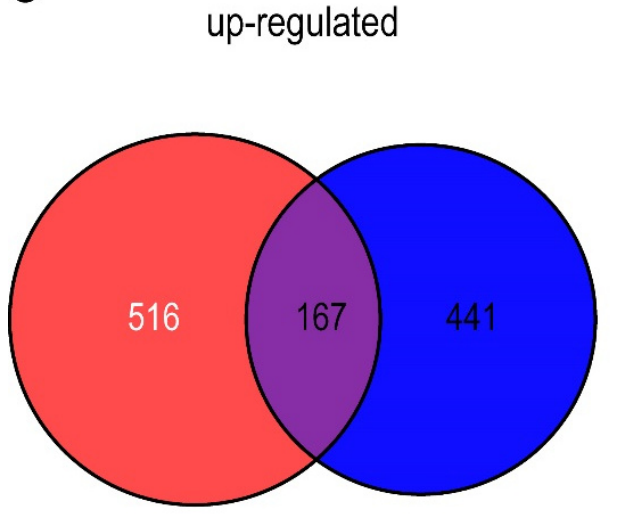

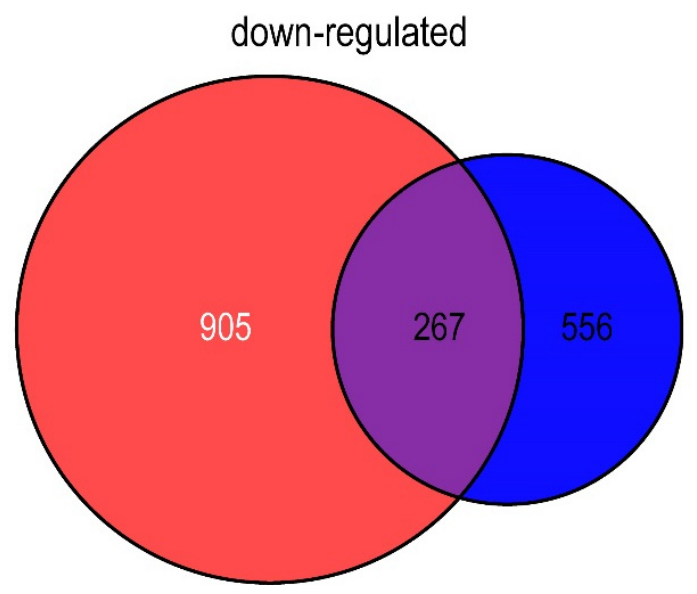

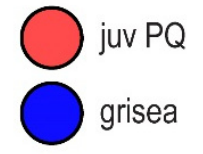

FIGURE 6: Effect of copper and $\mathrm{PQ}$ on lifespan and growth. (A) Lifespan of $P$. anserina on $\mathrm{M} 2$ medium supplemented with $20 \mu \mathrm{M} P Q$ ( $\mathrm{n}=$ 20; median lifespan = 56.5 days; $p<0.001), 100 \mu \mathrm{M} \mathrm{PQ}(\mathrm{n}=20$; median lifespan = 21.6 days; $p<0.001), 200 \mu \mathrm{M} P Q P Q(n=20 ; \mathrm{median}$ lifespan $=3.5$ days; $p<0.001), 100 \mu \mathrm{M} \mathrm{CuSO}_{4}(\mathrm{n}=20$; median lifespan $=21.5$ days; $\mathrm{p}<0.001$ ) or $100 \mu \mathrm{M} \mathrm{PQ}$ and $100 \mu \mathrm{M}$ CuSO $\mathrm{Combined}(\mathrm{n}$ $=3.8$; median lifespan $=3$ days; $\mathrm{p}<0.001)$. P-values were determined in comparison with untreated control $(\mathrm{n}=20 ;$ median lifespan $=27$ days) by 2-tailed Wilcoxen rank sum test. (B) The growth distance of cultures from (A) was measured after 10 days on $\mathrm{M} 2$ medium. $\mathrm{n}=20$. P-Value against control or as indicated was determined by 2-tailed Wilcoxen rank sum test. (C) Differential transcript abundance of the wild type grown under PQ-stress and in the grisea mutant grown without additional PQ is depicted in Venn diagrams of up- (left) or down- (right) regulated transcripts (factor $<3 ; \mathrm{pV}<0.01$ ) during $\mathrm{PQ}$-stress in juvenile $P$. anserina and in the mutant grisea. 


\section{MATERIALS AND METHODS}

\section{Determination of hydrogen peroxide release}

Measurement of hydrogen peroxide release was performed according to [56]. After germination for 2 days at $27^{\circ} \mathrm{C}$ in the dark on germination medium (standard cornmeal agar supplemented with $60 \mathrm{mM}$ ammonium acetate [9], $P$. anserina was grown for 11 days on $\mathrm{M} 2$ medium (senescent) or used directly (juvenile). A piece from the growth front was transferred to a M2 plate (M2 medium: $0.25 \mathrm{~g} / \mathrm{L} \mathrm{KH}_{2} \mathrm{PO}_{4}, 0.3 \mathrm{~g} / \mathrm{L}$ $\mathrm{K}_{2} \mathrm{HPO}_{4}, 0.25 \mathrm{~g} / \mathrm{L} \mathrm{MgSO}{ }_{4} \times 7 \mathrm{H}_{2} \mathrm{O}, 0.5 \mathrm{~g} / \mathrm{L}$ urea and $10 \mathrm{~g} / \mathrm{L}$ yellow dextrin. Addition of $2.5 \mathrm{mg} / \mathrm{L}$ biotin, $50 \mathrm{mg} / \mathrm{L}$ thiamine, 5 $\mathrm{mg} / \mathrm{L}$ citric acid $\times 1 \mathrm{H}_{2} \mathrm{O}, 5 \mathrm{mg} / \mathrm{L} \mathrm{ZnSO}_{4} \times 7 \mathrm{H}_{2} \mathrm{O}, 1 \mathrm{mg} / \mathrm{L}$ $\mathrm{Fe}\left(\mathrm{NH}_{4}\right)_{2}\left(\mathrm{SO}_{4}\right)_{2} \times 6 \mathrm{H}_{2} \mathrm{O}, 2.5 \mathrm{mg} / \mathrm{L} \mathrm{CuSO}_{4} \times 5 \mathrm{H}_{2} \mathrm{O}, 25 \mathrm{mg} / \mathrm{L}$ $\mathrm{MnSO}_{4} \times 1 \mathrm{H}_{2} \mathrm{O}, 50 \mathrm{mg} / \mathrm{L} \mathrm{Na}_{2} \mathrm{MoO}_{4} \times 2 \mathrm{H}_{2} \mathrm{O}$ and $50 \mathrm{mg} / \mathrm{L} \mathrm{H}_{3} \mathrm{BO}_{3}$ (after sterilization of the basal medium) supplemented with 0 , 10 or $20 \mu \mathrm{M}$ paraquat ( $\mathrm{PQ}$, Sigma-Aldrich, 856177) and grown for 4 days at $27^{\circ} \mathrm{C}$ and permanent light. Plates were flooded with a solution containing $2.5 \mathrm{mM}$ 3,3-diaminobenzidine (DAB, Sigma-Aldrich), $0.02 \mathrm{mg} / \mathrm{ml}$ horseradish peroxidase (Sigma) and $100 \mathrm{mM}$ Tris, $\mathrm{pH} 6.9$ and incubated $3 \mathrm{~h}$ in the dark at $27^{\circ} \mathrm{C}$. The staining solution was removed and the plate photographed.

Quantitative measurement of hydrogen peroxide was performed as described [7]. For this measurement, $P$. anserina was cultivated in a similar manner as before, but on $\mathrm{M} 2$ medium instead of PASM [57] and to a final age of $6 d, 11$ days and $15 \mathrm{~d}$.

\section{Cloning of $\boldsymbol{P}$. anserina HyPer-strains}

The generation of $P$. anserina HyPer strains was performed by two fragment ligation. The fragment containing the HyPer gene was amplified using oligonucleotides HyPer-fwd (5'CATTCGTTGGGGGATCCACC-3', Eurofins MWG Operon, Ebersberg, Germany) with restriction site BamHI and HyPer-rws (5'CGTCTAGATTAAACCGCCTGTTTAA-3', Eurofins MWG Operon) with restriction site $\mathrm{Xbal}$ and $\mathrm{pHyPer-dMito} \mathrm{(Evrogen)} \mathrm{as} \mathrm{tem-}$ plate. The amplified product and the vector pExMtterhph [8] were digested with BamHI (Thermo Scientific, ER0051) and Xbal (Thermo Scientific, ER0681). The plasmid was ligated and used to transform $P$. anserina wild-type spheroplasts as described $[58,59]$. Transformants were selected on hygromycin B supplemented medium.

\section{Measurement of cytoplasmic in vivo $\mathrm{H}_{2} \mathrm{O}_{2}$-levels}

$P$. anserina was germinated as previously described and grown for 4 days on M2 medium. Cylindrical pieces of agar containing 6 days old $P$. anserina cultures were punched out of the plate, transferred into a 96-well plate and surrounded with $60 \mu \mathrm{l} \mathrm{H}_{2} \mathrm{O}$. The fluorescence emission of the mycelium after exitation at $488 \pm 5 \mathrm{~nm}$ (oxidized HyPer) and $420 \pm 5 \mathrm{~nm}$ (reduced HyPer) was measured in a three minute interval at $530 \pm 20 \mathrm{~nm}$ (Tecan, Safire2). The relative $\mathrm{H}_{2} \mathrm{O}_{2}$ levels are the average of the quotient of emission at $530 \pm 20 \mathrm{~nm}$ of oxidized (excitation at $488 \pm 5 \mathrm{~nm}$ ) and reduced (excitation at $420 \pm 5 \mathrm{~nm}$ ) HyPer of three replicates of the treated probes substracted by the average quotient of the untreated control.

\section{RNA isolation}

For transcriptome analysis three monokaryotic $P$. anserina ascospores of the wild-type " $s$ " strain were germinated 2 days in the dark at $27^{\circ} \mathrm{C}$. These cultures were directly used or - in order to generate strains of older age - grown for 4 days (mid- dle-aged) and 8 days (senescent) under permanent light at $27^{\circ} \mathrm{C}$ on solid PASM medium. Subsequently, pieces of mycelium from the growth front of the PASM plates or directly from the germination plate (for juvenile cultures) were transferred onto solid PASM medium overlaid with a cellophane sheet and grown for 2 days (juvenile cultures) or for 3 days (middle-aged and senescent cultures) to obtain sufficient amounts of mycelium. The mycelium was scraped off, transferred to Erlenmeyer flasks containing liquid complete medium (CM: $70 \mathrm{mM}$ $\mathrm{NH}_{4} \mathrm{Cl}, 7.3 \mathrm{mM} \mathrm{KH}_{2} \mathrm{PO}_{4}, 6.7 \mathrm{mM} \mathrm{KCl}, 2 \mathrm{mM} \mathrm{MgSO}_{4}, 1 \%$ glucose, $0.2 \%$ tryptone, $0.2 \%$ yeast extract, $5 \mathrm{mM} \mathrm{FeCl}_{2}, 3.5 \mathrm{mM} \mathrm{ZnSO}_{4}$, $6.2 \mathrm{mM} \mathrm{MnCl}_{2}, \mathrm{pH} 6.5$ ) and incubated at $27^{\circ} \mathrm{C}$ in permanent light and shaking, according to [9]. After $24 \mathrm{~h}, \mathrm{PQ}$ was added to final concentration of $200 \mu \mathrm{M}$ and probes where shaken for $24 \mathrm{~h}$. This procedure results in cultures with a final age of 6 days (juvenile), 11 days (middle-aged) and 15 days (senescent). The lifespans of the three isolates on PASM were recorded to ensure that they have a similar aging behavior. All three isolates had a lifespan of 15 days. Total RNA was isolated using a $\mathrm{CsCl}$ density gradient as previously described [23].

\section{SuperSAGE analysis}

SuperSAGE analysis was performed by GenXPro GmbH (Frankfurt, Germany). Sequence tag identification and annotation were carried out as described [23]. The relative gene expression was calculated by comparison of tpm of PQ-stressed samples with transcriptome data of untreated cultures (control) [19]. The following factors were calculated: juv $P Q$, tpm 6 days $\mathrm{PQ} / \mathrm{tpm} 6$ days control; ma PQ, tpm 6 days $\mathrm{PQ} / \mathrm{tpm} 6$ days control; sen $\mathrm{PQ}$, tpm 15 days $\mathrm{PQ} / \mathrm{tpm} 14$ days control; aging: tpm 14 days control/ tpm 6 days.

\section{Gene ontology}

Gene ontology analysis was performed as described [19].

\section{Isolation of total protein extracts}

Mycelial pieces from freshly germinated ascospores were transferred to M2 plates for 4 days (ma) or $7-9$ days (sen). Subsequently, a piece of mycelium from the growth front was spread on a fresh M2 plate, overlaid with cellophane and grown for 3 days. To obtain juvenile cultures, germinated fungi were directly spread on $\mathrm{M} 2$ plates overlaid with cellophane and grown for 2 days. All cultures were transferred into Erlenmeyer flasks containing liquid complete medium and grown for 2 days to generate enough material. PQ was added to the indicated samples to a final concentration of $200 \mu \mathrm{M}$, $24 \mathrm{~h}$ before isolation. All incubation steps were performed at $27^{\circ} \mathrm{C}$ and permanent light, except germination which was executed in the dark. Proteins were isolated by grinding the mycelium under liquid $\mathrm{N}_{2}$ as described [10].

\section{Determination of SOD activity}

For SOD activity determination in protein extracts an SOD determination kit 19160 (Fluka Analytical) was used. 1 Hg protein extract was used per sample. The kinetic of pigment formation was recorded continuously in a 96-well plate reader (Tecan, Safire2) at $27^{\circ} \mathrm{C}$. SOD activity was calculated during linear reaction. 
Quantitative photometric measurement of catalase activity In vitro measurement of $\mathrm{H}_{2} \mathrm{O}_{2}$ degradation was carried out as described [36]. The $\triangle P a C a t B$-strain was used as a control [36]. $100 \mu \mathrm{g}$ of total protein extracts were used.

\section{Quantitative Real-Time PCR (qRT-PCR)}

Total RNA of the $P$. anserina wild type (the three RNA samples isolated for Super-SAGE analysis) was DNase digested with RNA-Plant kit (Machery-Nagel). Reverse transcription of $1 \mu \mathrm{g}$ of DNase free RNA was performed using iscript kit (BioRad). The cDNA was diluted to a concentration of $10 \mathrm{ng} / \mu \mathrm{l}$ and 20 ng were used per qRT-PCR reaction (IQ SybrGreen SuperMix, Biorad). Three technical replicates were performed for each sample. The primers summarized in Table S2 were used as indicated. The PCR efficiency was determined as described [60]. The relative expression was normalized to the reference genes PaPorin and PaRpl19 with the following formula:

Relative expression

$(\operatorname{root}(\mathrm{E}($ Porin $) \wedge \mathrm{CP}($ Porin)*E(Rpl19)^CP(Rpl19)))/(E(target gene $)^{\wedge} \mathrm{CP}($ target gene)) with E: PCR-Efficiency and CP: crossing point.

\section{Determination of respiration}

Juvenile fungi were cultivated as described above. Small pieces of mycelium (dry weight 2 to $9 \mathrm{mg}$ ) were transferred into a high resolution respirometer (Oxygraph2-k, OROBOROS) and oxygen consumption was measured in $\mathrm{CM}$ medium. SHAM (Salicylhydroxamic acid, Sigma-Aldrich) and KCN were added to a final concentration of $4 \mathrm{mM}$ and $1 \mathrm{mM}$, respectively, to inhibit respiration via complex IV and PaAOX respectively and to determine the portion of $A O X$ dependent respiration.

\section{Lifespan determination}

Lifespan of isolates was determined on M2 medium as described [61]. After germination of monokaryotic ascospores, a piece of mycelium was transferred to control M2 medium and $\mathrm{M} 2$ medium supplemented with $20 \mu \mathrm{M}, 100 \mu \mathrm{M}$ and $200 \mu \mathrm{M}$ $\mathrm{PQ}, 100 \mu \mathrm{M} \mathrm{CuSO}_{4}$ and $100 \mu \mathrm{M} \mathrm{PQ}$ and $100 \mu \mathrm{M} \mathrm{CuSO}{ }_{4}$ combined. $P$. anserina was grown at $27^{\circ} \mathrm{C}$ under permanent light.

\section{REFERENCES}

1. Harman D (1972). The biologic clock: the mitochondria? J Am Geriatr Soc 20: 145-147.

2. Doonan R, McElwee JJ, Matthijssens F, Walker GA, Houthoofd K, Back P, Matscheski A, Vanfleteren JR, and Gems D (2008). Against the oxidative damage theory of aging: Superoxide dismutases protect against oxidative stress but have little or no effect on life span in Caenorhabditis elegans. Genes Dev 22: 3236-3241.

3. Lapointe J and Hekimi S (2010). When a theory of aging ages badly. Cell Mol Life Sci 67: 1-8.

4. Levine RL and Stadtman ER (2001). Oxidative modification of proteins during aging. Exp Gerontol 36: 1495-1502.

5. Petropoulos I and Friguet B (2006). Maintenance of proteins and aging: the role of oxidized protein repair. Free Radic Res 40: 12691276.

6. Baraibar MA, Ladouce R, and Friguet B (2013). Proteomic quantification and identification of carbonylated proteins upon oxidative stress and during cellular aging. J Proteomics 92: 63-70.

\section{Statistical analysis of data}

Calculation of expected value for common regulation were done with: $E(x)=n^{*} M / N$, where $n$ and $M$ are the number of regulated genes and $\mathrm{N}$ is the total number of genes. Independence and odds ratio were calculated using Fisher's exact test. All other statistical calculations were done with student's t-test or Wilcoxen rank sum test, as indicated. Asterisks indicate $\mathrm{p}$-values: ${ }^{*} \mathrm{p}<0.05,{ }^{* *} \mathrm{p}<0.01,{ }^{* * *} \mathrm{p}<0.001$.

\section{ACKNOWLEDGMENTS}

We thank Oliver Philipp for performing a GO enrichment analysis. This work was supported by a grant (Os75/13-1) of the Deutsche Forschungsgemeinschaft (Bonn, Bad-Godesberg, Germany).

\section{SUPPLEMENTAL MATERIAL}

All supplemental data for this article are available online at www.microbialcell.com.

\section{CONFLICT OF INTEREST}

The authors declare no conflict of interest.

\section{COPYRIGHT}

(C) 2014 Wiemer and Osiewacz. This is an open-access article released under the terms of the Creative Commons Attribution (CC BY) license, which allows the unrestricted use, distribution, and reproduction in any medium, provided the original author and source are acknowledged.

Please cite this article as: Matthias Wiemer and Heinz D. Osiewacz (2014). Effect of paraquat-induced oxidative stress on gene expression and aging of the filamentous ascomycete Podospora anserine. Microbial Cell 1(7): 225-240. doi: 10.15698/mic2014.07.155

7. Kowald A, Hamann A, Zintel S, Ullrich S, Klipp E, and Osiewacz HD (2012). A systems biological analysis links ROS metabolism to mitochondrial protein quality control. Mech Ageing Dev 133: 331-337.

8. Luce K and Osiewacz HD (2009). Increasing organismal healthspan by enhancing mitochondrial protein quality control. Nat Cell Biol 11: 852-858.

9. Esser K (1974). Podospora anserina. In: Handbook of Genetics, King,R.C., ed, Plenum Press, New York; pp. 531-551

10. Osiewacz HD, Hamann A, and Zintel S (2013). Assessing organismal aging in the filamentous fungus Podospora anserina. Methods Mol Biol 965: 439-462.

11. Osiewacz HD, Hermanns J, Marcou D, Triffi M, and Esser K (1989). Mitochondrial DNA rearrangements are correlated with a delayed amplification of the mobile intron ( $p$ IDNA) in a long-lived mutant of Podospora anserina. Mutat Res 219: 9-15.

12. Borghouts C, Werner A, Elthon T, and Osiewacz HD (2001). Copper-modulated gene expression and senescence in the filamentous fungus Podospora anserina. Mol Cell Biol 21: 390-399. 
13. Scheckhuber CQ, Houthoofd K, Weil AC, Werner A, De Vreese A, Vanfleteren JR, and Osiewacz HD (2011). Alternative oxidase dependent respiration leads to an increased mitochondrial content in two long-lived mutants of the ageing model Podospora anserina. PLoS One 6: e16620.

14. Borghouts C, Scheckhuber CQ, Werner A, and Osiewacz HD (2002). Respiration, copper availability and SOD activity in $P$. anserina strains with different lifespan. Biogerontology 3: 143-153.

15. Fischer F, Weil A, Hamann A, and Osiewacz HD (2013). Human CLPP reverts the longevity phenotype of a fungal ClpP deletion strain. Nat Commun 4: 1397.

16. Weil A, Luce K, Dröse S, Wittig I, Brandt U, and Osiewacz HD (2011). Unmasking a temperature-dependent effect of the $P$. anserina $i-A A A$ protease on aging and development. Cell Cycle 10: 4280-4290.

17. Scheckhuber $C Q$, Erjavec N, Tinazli A, Hamann A, Nyström T, and Osiewacz HD (2007). Reducing mitochondrial fission results in increased life span and fitness of two fungal ageing models. Nat Cell Biol 9: 99-105.

18. Knuppertz L, Hamann A, Pampaloni F, Stelzer E, and Osiewacz HD (2014). Identification of autophagy as a longevity-assurance mechanism in the aging model Podospora anserina. Autophagy 10: 822-834.

19. Philipp O, Hamann A, Servos J, Werner A, Koch I, and Osiewacz HD (2013). A genome-wide longitudinal transcriptome analysis of the aging model Podospora anserina. PLoS ONE 8: e83109.

20. Hamann A, Brust D, and Osiewacz HD (2007). Deletion of putative apoptosis factors leads to lifespan extension in the fungal ageing model Podospora anserina. Mol Microbiol 65: 948-958.

21. Brust D, Daum B, Breunig C, Hamann A, Kühlbrandt W, and Osiewacz HD (2010). Cyclophilin D links programmed cell death and organismal aging in Podospora anserina. Aging Cell 9: 761-775.

22. Gredilla R, Grief J, and Osiewacz HD (2006). Mitochondrial free radical generation and lifespan control in the fungal aging model Podospora anserina. Exp Gerontol 41: 439-447.

23. Servos J, Hamann A, Grimm C, and Osiewacz HD (2012). A differential genome-wide transcriptome analysis: impact of cellular copper on complex biological processes like aging and development. PLoS ONE 7: e49292.

24. Cocheme HM and Murphy MP (2008). Complex I is the major site of mitochondrial superoxide production by paraquat. J Biol Chem 283: 1786-1798.

25. Castello PR, Drechsel DA, and Patel M (2007). Mitochondria are a major source of paraquat-induced reactive oxygen species production in the brain. J Biol Chem 282: 14186-14193.

26. Belousov VV, Fradkov AF, Lukyanov KA, Staroverov DB, Shakhbazov KS, Terskikh AV, and Lukyanov S (2006). Genetically encoded fluorescent indicator for intracellular hydrogen peroxide. Nat Methods 3: 281-286.

27. Van Remmen $\mathrm{H}$ and Richardson A (2001). Oxidative damage to mitochondria and aging. Exp Gerontol 36: 957-968.

28. Kawalek A, Lefevre SD, Veenhuis M, and van der Klei IJ (2013). Peroxisomal catalase deficiency modulates yeast lifespan depending on growth conditions. Aging (Albany NY) 5: 67-83.

29. Rattan SI (2013). Healthy ageing, but what is health? Biogerontology 14: 673-677.

30. Calabrese EJ (2013). Hormesis: Toxicological foundations and role in aging research. Exp Gerontol 48: 99-102.
31. Ristow $M$ and Schmeisser $S$ (2011). Extending life span by increasing oxidative stress. Free Radic Biol Med 51: 327-336.

32. Starkov AA (2008). The role of mitochondria in reactive oxygen species metabolism and signaling. Ann N Y Acad Sci 1147: 37-52.

33. Coppin E and Silar P (2007). Identification of PaPKS1, a polyketide synthase involved in melanin formation and its use as a genetic tool in Podospora anserina. Mycol Res 111: 901-908.

34. Missall TA, Lodge JK, and McEwen JE (2004). Mechanisms of resistance to oxidative and nitrosative stress: implications for fungal survival in mammalian hosts. Eukaryot Cell 3: 835-846.

35. Zou S, Meadows S, Sharp L, Jan LY, and Jan YN (2000). Genomewide study of aging and oxidative stress response in Drosophila melanogaster. Proc Natl Acad Sci U S A 97: 13726-13731.

36. Zintel S, Bernhardt D, Rogowska-Wrzesinska A, and Osiewacz HD (2011). PaCATB, a secreted catalase protecting Podospora anserina against exogenous oxidative stress. Aging (Albany NY) 3: 768-781.

37. Britton G (1995). Structure and properties of carotenoids in relation to function. FASEB J 9: 1551-1558.

38. Strobel I, Breitenbach J, Scheckhuber CQ, Osiewacz HD, and Sandmann G (2009). Carotenoids and carotenogenic genes in Podospora anserina: engineering of the carotenoid composition extends the life span of the mycelium. Curr Genet 55: 175-184.

39. Borghouts $C$ and Osiewacz HD (1998). GRISEA, a coppermodulated transcription factor from Podospora anserina involved in senescence and morphogenesis, is an ortholog of MAC1 in Saccharomyces cerevisiae. Mol Gen Genet 260: 492-502.

40. Osiewacz HD and Nuber U (1996). GRISEA, a putative copperactivated transcription factor from Podospora anserina involved in differentiation and senescence. Mol Gen Genet 252: 115-124.

41. Borghouts C, Scheckhuber CQ, Stephan O, and Osiewacz HD (2002). Copper homeostasis and aging in the fungal model system Podospora anserina: differential expression of PaCtr3 encoding a copper transporter. Int J Biochem Cell Biol 34: 1355-1371.

42. Averbeck NB, Borghouts C, Hamann A, Specke V, and Osiewacz HD (2001). Molecular control of copper homeostasis in filamentous fungi: increased expression of a metallothionein gene during aging of Podospora anserina. Mol Gen Genet 264: 604-612.

43. Scheckhuber CQ, Grief J, Boilan E, Luce K, Debacq-Chainiaux F, Rittmeyer C, Gredilla R, Kolbesen BO, Toussaint O, and Osiewacz HD (2009). Age-related cellular copper dynamics in the fungal ageing model Podospora anserina and in ageing human fibroblasts. PLoS One 4: e4919.

44. Schrettl $M$ and Haas $H$ (2011). Iron homeostasis--Achilles' heel of Aspergillus fumigatus? Curr Opin Microbiol 14: 400-405.

45. Bleackley MR and MacGillivray RT (2011). Transition metal homeostasis: from yeast to human disease. Biometals 24: 785-809.

46. Haas H (2012). Iron - A key nexus in the virulence of Aspergillus fumigatus. Front Microbiol 3: 28.

47. Cobine PA, Ojeda LD, Rigby KM, and Winge DR (2004). Yeast contain a non-proteinacious pool of copper in the mitochondrial matrix. J Biol Chem: 14447-14455.

48. Vest KE, Leary SC, Winge DR, and Cobine PA (2013). Copper import into the mitochondrial matrix in Saccharomyces cerevisiae is mediated by Pic2, a mitochondrial carrier family protein. J Biol Chem 288: 23884-23892. 
49. Barhoom S, Kupiec M, Zhao X, Xu JR, and Sharon A (2008). Functional characterization of CgCTR2, a putative vacuole copper transporter that is involved in germination and pathogenicity in Colletotrichum gloeosporioides. Eukaryotic Cell 7: 1098-1108.

50. Rees EM, Lee J, and Thiele DJ (2004). Mobilization of intracellular copper stores by the ctr2 vacuolar copper transporter. J Biol Chem 279: 54221-54229.

51. Groebe K, Krause F, Kunstmann B, Unterluggauer $H$, Reifschneider NH, Scheckhuber CQ, Sastri C, Stegmann W, Wozny W, Schwall GP, Poznanovic S, Dencher NA, Jansen-Dürr $P$, Osiewacz $H D$, and Schrattenholz A (2007). Differential proteomic profiling of mitochondria from Podospora anserina, rat and human reveals distinct patterns of age-related oxidative changes. Exp Gerontol 42: 887-898.

52. Kroemer G, Galluzzi L, and Brenner C (2007). Mitochondrial membrane permeabilization in cell death. Physiol Rev 87: 99-163.

53. Davies KM, Strauss M, Daum B, Kief JH, Osiewacz HD, Rycovska A, Zickermann V, and Kühlbrandt $W$ (2011). Macromolecular organization of ATP synthase and complex I in whole mitochondria. Proc Natl Acad Sci U S A 108: 14121-14126.

54. Daum B, Walter A, Horst A, Osiewacz HD, and Kühlbrandt W (2013). Age-dependent dissociation of ATP synthase dimers and loss of inner-membrane cristae in mitochondria. Proc Natl Acad Sci U S A 110: 15301-15306.
55. Boilan E, Winant V, Dumortier E, Piret JP, Bonfitto F, Osiewacz HD, Debacq-Chainiaux F, and Toussaint $O$ (2013). Role of p38MAPK and oxidative stress in copper-induced senescence. Age 35: 2255-2271.

56. Munkres KD (2014). Histochemical detection of superoxide radicals and hydrogen peroxide by Age-1 mutants of Neurospora. Fungal Genet Newsl: 24-25.

57. Brust D, Hamann A, and Osiewacz HD (2010). Deletion of PaAif2 and PaAmid2, two genes encoding mitochondrial AIF-like oxidoreductases of Podospora anserina, leads to increased stress tolerance and lifespan extension. Curr Genet 55: 225-235.

58. Stumpferl SW, Stephan O, and Osiewacz HD (2004). Impact of a disruption of a pathway delivering copper to mitochondria on Podospora anserina metabolism and life span. Eukaryotic Cell 3: 200211.

59. Osiewacz HD, Skaletz A, and Esser K (1991). Integrative transformation of the ascomycete Podospora anserina: identification of the mating-type locus on chromosome VII of electrophoretically separated chromosomes. Appl Microbiol Biotechnol 35: 38-45.

60. Pfaffl MW (2001). A new mathematical model for relative quantification in real-time RT-PCR. Nucleic Acids Res 29: e45.

61. Kunstmann B and Osiewacz HD (2008). Over-expression of an Sadenosylmethionine-dependent methyltransferase leads to an extended lifespan of Podospora anserina without impairments in vital functions. Aging Cell 7: 651-662. 